\title{
Algo más que monoaminas en el tratamiento de la depresión: Mecanismos neurobiológicos emergentes de los antidepresivos del siglo XXI
}

\author{
Cecilio Álamo ${ }^{1, *}$, Cristina Zaragozá ${ }^{2}$ y Francisco López-Muñoz ${ }^{3,4}$ \\ 1 Departamento de Ciencias Biomédicas, Facultad de Medicina y Ciencias de la Salud, Universidad de \\ Alcalá; https://orcid.org/0000-0001-7652-7931 \\ 2 Departamento de Ciencias Biomédicas, Facultad de Medicina y Ciencias de la Salud, Universidad de \\ Alcalá; https://orcid.org/0000-0002-4768-6797 \\ 3 Facultad de Ciencias de la Salud, Universidad Camilo José Cela; https://orcid.org/0000-0002-5188-6038 \\ 4 Unidad de Neuropsicofarmacología, Instituto de Investigación Hospital 12 de Octubre \\ * Autor correspondencia: cecilio.alamo@uah.es
}

DOI: https://doi.org/10.37536/RIECS.2020.5.2.214

Recibido: 27/05/2020; Aceptado: 25/07/2020; Publicado: 30/11/2020

Resumen: Clásicamente, el tratamiento farmacológico de la depresión se ha realizado con antidepresivos monoaminérgicos, que presentan una serie de limitaciones, como un lento inicio de acción, una inadecuada respuesta antidepresiva, disfunción sexual o tolerabilidad mejorable. En esta revisión analizaremos nuevos mecanismos fisiopatológicos implicados en la depresión como dianas para la búsqueda de antidepresivos diferentes. En el ámbito de la endocrinología los resultados son desalentadores, efímeros (TRH), limitados (hormonas tiroideas), dudosos (antagonistas CRH1), controvertidos (estrógenos) o poco eficaces (andrógenos). Varios neuropéptidos están implicados en la patogenia de la depresión, como la hormona antidiurética, la oxitocina, la sustancia $\mathrm{P}$, el neuropéptido $\mathrm{Y}$ o la galanina, pero su abordaje desde el punto de vista terapéutico no ha dado resultados terapéuticos. La relación entre depresión y procesos inflamatorios es patente, pero los datos de eficacia, muchas veces anecdóticos, de algunos antiinflamatorios, antagonistas de TNF o anticuerpos monoclonales no pueden generalizarse. La participación del sistema opioide endógeno también se ha explorado, pero su potencial adictivo hace que no dispongamos en estos momentos "opioides antidepresivos". La hipótesis glutamatérgica de la depresión ha sido trabajada durante más de 3 décadas y por fin parece que ha dado resultados: la esketamina, un isómero de la ketamina, ha demostrado, gracias a un programa de desarrollo clínico robusto, que es un antidepresivo de acción rápida, eficaz en depresión resistente, con una tolerabilidad aceptable, lo que ha motivado su autorización en depresión resistente en asociación con antidepresivos convencionales. La esketamina es la respuesta terapéutica a la "hipótesis glutamatérgica de la depresión".

Palabras Clave: Alopregnanolona, Antidepresivos, Depresión, Hipótesis glutamatérgica, Ketamina, Esketamina, Riluzol.

\begin{abstract}
Classically, the pharmacological treatment of depression has been carried out with monoaminergic antidepressants, which present a series of limitations, such as a slow onset of action, an inadequate antidepressant response, sexual dysfunction or a tolerability that can be improved. In this review we will analyze new pathophysiological mechanisms involved in depression as targets for the search for different antidepressants. In the field of endocrinology, the results are disappointing, ephemeral (TRH), limited (thyroid hormones), doubtful (CRH1 antagonists), controversial (estrogens) or not very effective (androgens). Several neuropeptides are implicated in the pathogenesis of depression, such as antidiuretic hormone, oxytocin, substance $P$, neuropeptide $\mathrm{Y}$ or galanin, but their therapeutic approach has not yielded therapeutic results. The relationship
\end{abstract}


between depression and inflammatory processes is clear, but the efficacy data, often anecdotal, of some anti-inflammatory drugs, TNF antagonists or monoclonal antibodies cannot be generalized. The participation of the endogenous opioid system has also been explored, but its addictive potential means that we do not currently have "antidepressant opioids". The glutamatergic hypothesis of depression has been working for more than 3 decades and finally seems to have given results: esketamine, an isomer of ketamine, has shown, thanks to a robust clinical development program, that it is an fast-acting antidepressant, effective in resistant depression, with an acceptable tolerability, which has motivated its authorization in resistant depression in association with conventional antidepressants. Esketamine is the therapeutic answer to the "glutamatergic hypothesis of depression".

Key words: Allopregnanolone, Antidepressants, Depression, Esketamine, Glutamatergic hypothesis, Ketamine, Riluzole.

\section{Introducción}

Durante la década de 1950 fueron introducidos en clínica los dos primeros medicamentos específicamente antidepresivos: la iproniazida, un inhibidor de la monoaminooxidasa (IMAO) [1] y la imipramina, el primer fármaco de la familia de los antidepresivos tricíclicos (ADT) [2]. Estos antidepresivos modificaron el desarrollo de la psiquiatría desde el punto de vista sanitario y social, cambiando la atención psiquiátrica de los pacientes depresivos. Además, estos agentes han constituido un instrumento de investigación indispensable para el conocimiento, si bien solo parcial, de la neurobiología de la depresión, permitiendo postular la primera hipótesis etiopatogénica de los trastornos depresivos, "la hipótesis monoaminérgica", basada en una disfunción de la neurotransmisión de las principales monoaminas, noradrenalina (NA), serotonina (5-HT) y dopamina (DA) [3-6], que ha liderado durante más de medio siglo la fisiopatología y el tratamiento de la depresión [7].

En la década de 1970 aparecieron nuevos antidepresivos heterocíclicos, denominados "antidepresivos atípicos" o "de segunda generación", entre los que aún tienen vigencia la maprotilina, mianserina o trazodona, que constituyeron una transición hasta la introducción, a finales de la década de 1980, de los inhibidores selectivos de la recaptación de serotonina (ISRS), cuyo representante más popular fue la fluoxetina. Los ISRS presentan un perfil de tolerabilidad diferente al de los ADT, lo que facilitó el tratamiento de la depresión por parte de Atención Primaria [8]. Posteriormente, se introdujeron en clínica nuevas familias de antidepresivos, como los inhibidores de la recaptación de noradrenalina y serotonina (IRNS), entre los que se encuentra la venlafaxina, la duloxetina y la desvenlafaxina, los inhibidores de receptores alfa-2 adrenérgicos presinápticos, cuyo prototipo es la mirtazapina, y los inhibidores selectivos de la recaptación de noradrenalina (IRNA), con la reboxetina como único representante en España. Todos ellos exploran mecanismos monoaminérgicos y aumentan la tasa de monoaminas en la hendidura sináptica [4-6].

Además, existen algunos antidepresivos que actúan sobre dianas no aminérgicas, aunque no de forma totalmente selectiva. En la primera década del siglo XXI se comercializó la agomelatina, un agonista melatoninérgico que además bloquea los receptores serotoninérgicos 5-HT2A, lo que facilita la liberación de DA y NA en corteza prefrontal [9]. Más recientemente, el arsenal antidepresivo se ha visto incrementado con la vortioxetina, un antidepresivo denominado "multimodal", ya que afecta al funcionalismo de varias monoaminas, siendo su mecanismo principal una combinación de ISRS, antagonismo de receptores 5- $\mathrm{HT}_{3}$ y agonismo de receptores 5- $\mathrm{HT}_{1 \mathrm{~A}} \mathrm{y}$, por tanto, monoaminérgico también. Por último, se ha comercializado en España la tianeptina, presente en otros países desde hace más de dos décadas, que es un antidepresivo con un mecanismo complejo que implica al funcionalismo glutamatérgico, opioidérgico y la liberación de DA en el núcleo accumbens y la corteza prefrontal. Por tanto, estos antidepresivos también implican mecanismos monoaminérgicos [10]. 
Se postula que algunas de las limitaciones clínicas de los antidepresivos, como un lento inicio de acción, de dos semanas a dos meses, una inadecuada respuesta antidepresiva entre el 40 y el 50\% de los pacientes, la carencia de mejoría de la cognición, la inducción de disfunción sexual, junto a una tolerabilidad mejorable, podrían deberse al mecanismo común de acción que aumenta la tasa de monoaminas [11-12]. Por ello, si queremos antidepresivos más rápidos, eficaces en las depresiones resistentes, que mejoren la cognición y la anhedonia, debemos diseñar agentes con un mecanismo de acción que no dependa de modo exclusivo de las monoaminas [10].

\section{Material y Métodos}

La búsqueda bibliográfica para esta revisión se ha realizado fundamentalmente en el motor de búsqueda de Pub-Med de la National Library of Medicine (NLM) de Estados Unidos, que permite el acceso a las bases de datos MEDLINE y otras. Además, se han utilizado la base de datos "Clinical.Trials.gov", los recursos bibliográficos de la biblioteca de la Universidad de Alcalá. Con estos recursos bibliográficos la realización del trabajo ha sido a criterio de los autores.

\section{Visión ampliada de la neurobiología de la depresión. Estrategias para la búsqueda de nuevos antidepresivos no aminérgicos}

La hipótesis monoaminérgica de la depresión nos ha aportado muchos conocimientos sobre su neurobiología [13]. En la actualidad, conocer otros componentes neurológicos, endocrinológicos, metabólicos e inflamatorios implicados en la depresión puede aportar dianas terapéuticas para la búsqueda de nuevos y diferentes antidepresivos.

\subsection{Dianas endocrinológicas en la fisiopatología y tratamiento de la depresión}

La relación entre psiquiatría y endocrinología es bidireccional. Tanto los síntomas depresivos como los ansiosos son comunes en muchos pacientes con trastornos endocrinológicos y las alteraciones hormonales se presenta con frecuencia en los pacientes deprimidos. Por ello, la corrección de los trastornos hormonales se ha explorado como posible tratamiento antidepresivo [14].

Las hormonas tiroideas participan en el desarrollo y la función cerebral y algunas manifestaciones neuropsiquiátricas se asocian con alteraciones de las mismas. En pacientes con depresión se observan anomalías del eje hipotálamo-hipofiso-tiroideo, y en patologías tiroideas aparecen manifestaciones depresivas [15]. La hormona tiroidea se ha empleado como terapia de potenciación en pacientes con depresión resistente. En nuestro grupo, hemos puesto de manifiesto unas prometedoras, aunque efímeras, propiedades antidepresivas de la TRH (tyrotrophin releasing hormone) [16]. La relación terapéutica entre depresión y función tiroidea es una incógnita [17].

Los corticosteroides están muy relacionados con la depresión. El cortisol es considerado como la "hormona del estrés" y la relación de este con la depresión, tanto experimental como clínica, es incuestionable. La hiperestimulación de la hormona liberadora de corticotropina (CRH) parece ser un factor clave, tanto en el estrés crónico como en la depresión y los receptores $\mathrm{CRH}_{1}$ están implicados en la patofisiología de la depresión y ansiedad. Alteraciones del gen de este receptor se han relacionado con la depresión. Se ha pensado que los antagonistas de los receptores $\mathrm{CRH}_{1}$ serían dianas farmacológicas de nuevos antidepresivos. Sin embargo, pese a los muchos estudios prometedores, no contamos con ningún antagonista $\mathrm{CRH}_{1}$ con eficacia antidepresiva contrastada. Esta falta de eficacia podría deberse a dificultades galénicas de formulación que impediría a estos agentes atravesar la barrera hematoencefálica (BHE) [18] o a que solo sean eficaces en pacientes con alteraciones muy importantes de los sistemas de transducción de la CRH [19].

Las hormonas sexuales también se han implicado en la neurobiología de la depresión. Los trastornos del estado de ánimo son más frecuentes en los periodos de cambios hormonales importantes, como la pubertad, la menopausia y en el postparto. Los receptores estrogénicos, que se distribuyen de forma importante en el cerebro y participan en el desarrollo y maduración neuronal, podrían participar en la fisiopatología de los trastornos del estado de ánimo. Los estrógenos aumentan la actividad de la BDNF (brain derived neurotrophic factor) y modulan la neurotransmisión 
aminérgica (5-HT, NA, DA) y glutamatérgica. Sin embargo, el empleo de estrógenos en la depresión sigue siendo controvertido. Existen estudios en la perimenopausia favorables a la eficacia antidepresiva de los estrógenos [15]. Pero, un amplio meta-análisis arrojó resultados negativos [20]. Además, el uso de anticonceptivos hormonales o la terapia hormonal sustitutiva se vinculó con un riesgo significativamente mayor de depresión [21].

Los andrógenos son moduladores alostéricos de los receptores GABA-A por lo que influyen sobre varios sistemas de neurotransmisión neuronal, implicados en la neurobiología de los trastornos del estado de ánimo. La disminución, con la edad, de los niveles de testosterona se puede asociar a síntomas depresivos, estado de ánimo negativo, fatiga, irritabilidad y disminución de la libido. Además, los antiandrógenos, en varones, se asocian a la depresión, pero la testosterona como potenciador antidepresivo es ineficaz. Por el contrario, en mujeres con depresión resistente, dosis bajas de testosterona mejoran significativamente los síntomas depresivos respecto al placebo [15,22].

\subsection{Neuropéptidos como dianas potenciales de los antidepresivos}

La arginina-vasopresina (AVP), también conocida como hormona antidiurética, se sintetiza en el hipotálamo y actúa en el sistema nervioso central (SNC) a través de dos subtipos de receptores: V1A y V1B. La AVP participa en la fisiopatología de los trastornos del estado de ánimo debido a su capacidad de regular la actividad del eje hipotálamo-hipófiso-adrenal (HHA) a través de los receptores V1B. El bloqueo de estos receptores V1B extrahipotalámicos induce efectos antidepresivos y ansiolíticos en varios modelos experimentales conductuales. Además, alteraciones genéticas en el receptor AVP contribuyen a la aparición de depresión en humanos [23]. En depresión existen niveles elevados de AVP y el antagonista V1B (SSR149415) mejoró la sintomatología depresiva [24].

La oxitocina (OXT) es una hormona neuropeptídica hipofisaria, que desempeña el papel de neurotransmisor y neuromodulador en el SNC de los mamíferos y ha sido implicada en la fisiopatología de la depresión. En roedores, la OXT presenta propiedades antidepresivas, estimula el crecimiento neuronal y contrarresta la neurodegeneración inducida por corticosteroides o el estrés. En estudios preclínicos y clínicos, la OXT mejora la disfunción sexual, la anhedonia y los síntomas depresivos, lo que se achaca a una potenciación de la neurotransmisión dopaminérgica mesolímbica [15]. En pacientes deprimidos parece existir una correlación positiva entre niveles plasmáticos de OXT y emotividad positiva. En sujetos con fenotipo melancólico depresivo los niveles de OXT son más bajos [25]. Sin embargo, las concentraciones de OXT en líquido cefalorraquídeo (LCR) en deprimidos no son diferentes de los controles. Varios análogos de OXT se han estudiado en ensayos clínicos [26], pero ninguno ha sido comercializado. La OXT intranasal, asociada al escitalopram, en pacientes con depresión resistente, ha dado resultados positivos [23].

La sustancia P (SP) es un neuropéptido de 11 aminoácidos, que activa preferentemente el receptor de neuroquinina-1 (NK1), que se ha asociado con los trastornos afectivos y adicciones. Los antagonistas de los receptores NK1 fueron de las primeras alternativas al tratamiento antidepresivo no relacionado con las monoaminas. Estudios iniciales pusieron de manifiesto las propiedades antidepresivas de MK-869 [27], lo que abrió las puertas a la investigación clínica con otros antagonistas NK1, como aprepiptant, casopitant y orvepitant, con resultados prometedores en fase 2, pero decepcionantes en fase 3, en los que la respuesta era solo parcial o no superaba a la del placebo [15]. Además, la expresión de los receptores NK1 en pacientes con depresión no tratada no se diferencia de la de los controles [28], por lo que estos agentes se han discontinuado [29].

El neuropéptido Y (NPY) es un neurotransmisor muy extendido en el SNC y actúa sobre un amplio número de receptores (Y1 a Y6). Se ha comprobado que el NPY se encuentra disminuido en plasma y/o LCR en pacientes con depresión, ansiedad, trastorno de estrés postraumático o estrés. En la depresión, la disminución de NPY se limita al plasma, pero no al LCR [30]. El tratamiento antidepresivo se ha relacionado con el aumento de los niveles de NPY que activarían a los receptores Y2 para mediar el efecto antidepresivo [31], mientras que el efecto ansiolítico parece estar mediado por los receptores Y1 [32]. De momento, el NPY por su falta de especificidad es una [30].

La galanina (GAL) es un neuropéptido de 30 aminoácidos que se localiza con la NA en las neuronas del locus coeruleus (LC) y con la 5-HT en los núcleos del rafe. Se sabe que el estrés libera 
conjuntamente GAL con NA y 5-HT. Existen variaciones genéticas de GAL y de sus receptores asociadas a un mayor riesgo de depresión y ansiedad [33]. La GAL modula la función de los receptores 5-HT1A, receptores claves en el mecanismo de acción de los antidepresivos serotoninérgicos, existiendo heterodímeros de receptoriales 5HT1A-GAL1. Los receptores GAL1 y GAL3 median la acción antidepresiva, mientras que el estímulo de los receptores GAL2 provoca depresión en animales de experimentación. Además, la fracción GAL1-15 de la GAL regula al alza los receptores 5-HT1A, por lo que sería un agente potenciador de ISRS en depresión resistente [34]. Con varios ligandos de GAL se han encontrado resultados similares. Sin embargo, la relación neurobiológica de la GAL con la depresión es todavía muy incipiente [15].

\subsection{Inflamación: componente fisiopatológico y diana potencial para el tratamiento de la depresión}

Existen suficientes pruebas para implicar los procesos inflamatorios con la depresión. En plasma de pacientes deprimidos se observa un aumento de las citoquinas periféricas, TNF (tumor necrosis factor), interleucinas (IL-1 e IL-6) que pueden atravesar la BHE y actuar directamente sobre las neuronas y las células de glía. Estos mediadores inflamatorios se han relacionado con la función cerebral, con el estado anímico y con la cognición. Entre el $40 \%$ y el $50 \%$ de los pacientes tratados con interferón-alfa, que aumentan las concentraciones de TNF, IL-1 e IL-6, desarrollan un trastorno depresivo. Estos mecanismos podrían explicar por qué las personas con enfermedades autoinmunes e infecciones graves son más propensas a padecer depresión. Se ha hipotetizado que los agentes antiinflamatorios e inmunomoduladores serían eficaces en el tratamiento de la depresión [35-36].

Entre los antinflamatorios no esteroídicos (AINE), el celecoxib, un inhibidor selectivo de la COX2, ha sido el agente más utilizado, en la mayoría de estudios en asociación con antidepresivos (reboxetina, sertralina, fluoxetina), con resultados positivos, lo que se achaca a una disminución del nivel de IL-1. Con otros AINE y con paracetamol los datos cuestionan su relación beneficio riesgos [37]. Se han realizado estudios clínicos con antagonistas del TNF, utilizados en el tratamiento de enfermedades autoinmunes, en depresión bipolar. Algunos anticuerpos monoclonales, como adalimumab, infliximab y golimumab han mostrado efectos antidepresivos en pacientes con depresión comórbida con enfermedades inflamatorias crónicas, como la enfermedad de Crohn o la espondilitis anquilosante, en especial en pacientes con los niveles más altos de mediadores inflamatorios, por lo que su empleo debe limitarse a estos pacientes [38].

\subsection{Opioides en la fisiopatología y tratamiento potencial de la depresión}

Históricamente, los opioides fueron empleados en el manejo de los trastornos depresivos, incluso mucho antes de que en la década de 1950 se introdujeran los ADT y los IMAO. El sistema opioide endógeno procesa las recompensas ante estímulos naturales y sustancias de abuso. Además, la anhedonia, síntoma central de la depresión, se asocia al uso de opioides, por lo que el sistema opioide puede estar involucrado en la fisiopatología de la depresión [39].

El sistema opioide endógeno está formado por un grupo de péptidos, "opioides endógenos", endorfina, encefalinas y dinorfina, y por receptores acoplados a proteínas $\mathrm{G}$, mu, delta y kappa, con diferentes papeles fisiológicos. En estudios de neuroimagen, morfológicos y funcionales, se muestran alteraciones estructurales y funcionales opioidérgicas en corteza prefrontal, núcleo accumbens y corteza cingulada anterior de pacientes con depresión y comportamiento suicida [40-41].

Aunque tanto el uso indebido, como el tratamiento crónico en dosis altas con opioides, se han relacionado constantemente con el aumento de la incidencia, recaída y recurrencia de la depresión, existe la posibilidad de que algunos subtipos de opioides puedan ser de utilidad como terapia de la depresión. Sin embargo, algunos datos experimentales que implican a los receptores delta en la ansiedad y en la depresión no se han acompañado de eficacia en clínica humana. Del mismo modo, algunos estudios con moduladores de receptores kappa en la depresión, tampoco han dado resultados clínicamente relevantes [10]. En este sentido, ALKS-5461 (asociación de buprenorfina, agonista parcial mu, y samidorfano, antagonista kappa) está en desarrollo como antidepresivo, con resultados discordantes entre la fase 2 y 3 de los ensayos clínicos [42], por lo que su aprobación está 
pendiente de la Food and Drug Administration (FDA) [39]. Además, otros compuestos dotados de afinidad por distintos receptores opioides se encuentran en investigación como antidepresivos. En general, los resultados obtenidos con estos agentes en ensayos clínicos confirman que los compuestos multimodales, que actúan de forma conjunta sobre varios receptores opioides, pueden normalizar muchos de los endofenotipos básicos de la depresión. El hecho de ser agentes con propiedades adictivas hace que su uso clínico pase por criterios estrictos de control y farmacovigilancia [43].

En definitiva, la relación del sistema opioide endógeno con la fisiopatología de la depresión, no parece cuestionable. Los receptores delta están relacionados con la ansiedad y la depresión, pero los agentes capaces de actuar sobre estos receptores no se han traducido por una eficacia antidepresiva en humanos. Del mismo modo, el papel de los receptores kappa en la depresión es patente, estos receptores son la diana de las dinorfinas que se liberan por el estrés, pero de momento los moduladores kappa no han dado resultados clínicamente relevantes como antidepresivos [10].

\subsection{GABA en la fisiopatología de la depresión y su potencial terapéutico}

El ácido gamma amino-butírico (GABA) es el neurotransmisor inhibitorio más importante en el SNC, donde se mantiene en equilibrio con el glutamato (GLU). El sistema gabérgico interactúa con varios sistemas implicados en la fisiopatología de la depresión, sistema serotoninérgico, noradrenérgico y con el eje HHA. En roedores las alteraciones de los receptores metabotrópicos GABA-B se asocian con ansiedad y conducta depresiva. En humanos, las concentraciones de GABA son menores en pacientes con depresión y el tratamiento antidepresivo aumenta y recupera las concentraciones de GABA, lo que sugiere que este sistema de neurotransmisión podría tener un papel relevante fisiopatológico y terapéutico en la depresión [44-45].

El empleo de agentes terapéuticos que abordan el sistema gabérgico se limita a las benzodiazepinas, unos moduladores alostéricos positivos de los receptores ionotrópicos GABA-A, que se administran habitualmente, en asociación con otros antidepresivos, para mitigar la excitación, insomnio y ansiedad que se produce al inicio del tratamiento. Un meta-análisis indica que las benzodiazepinas son superiores al placebo y no inferiores a los ADT en la depresión ansiosa. Sin embargo, no existen comparaciones con los antidepresivos más modernos [46]. El receptor GABA-A, que es el receptor inhibidor más abundante en el cerebro, no es una diana terapéutica de importancia para el tratamiento en monoterapia de la depresión [39].

3.6. Mecanismos glutamatérgicos como diana trascendental en la fisiopatología y tratamiento de la depresión: la "hipótesis glutamatérgica de la depresión"

Los intentos por encontrar otros antidepresivos con mecanismos de acción no monoaminérgicos han sido intensos, pero los resultados han sido clínicamente poco [10,47-48]. Sin embargo, la exploración de los complejos mecanismos funcionales glutamatérgicos, además de dar información importante sobre la fisiopatología de la depresión y otras enfermedades mentales, ha aportado resultados interesantes, aunque todavía escasos, desde el punto de vista terapéutico.

En los últimos años, evidencias experimentales y clínicas implican al sistema glutamatérgico en la fisiopatología de la depresión. En efecto, existen una serie de hechos experimentales y clínicos que avalan que la modulación del funcionalismo glutamatérgico puede jugar un papel importante en el manejo de la depresión. La "hipótesis glutamatérgica de la depresión" se remonta a principios de la década de 1990. Trullas y Skolnick [49] observaron que los antagonistas del receptor N-metil-Daspartato (R-NMDA), como la fenciclidina o ketamina, presentaban una acción similar a la de los antidepresivos. En la actualidad, esta hipótesis permite implicar a este sistema en la patogenia de la depresión [7] y constituye una diana con posibilidades terapéuticas más que probables [50]. 


\subsubsection{Neurotransmisión y funcionalismo glutamatérgico}

El GLU o ácido L-glutámico es el principal neurotransmisor excitatorio en el SNC y se encuentra de forma activa en más de la mitad de las sinapsis cerebrales. El funcionalismo glutamatérgico está fundamentado en la denominada "sinapsis tripartita", integrada por una neurona presináptica, una neurona postsináptica y un astrocito microglial. En la neurona presináptica, el GLU es almacenado en vesículas sinápticas, de forma activa, por un transportador de GLU vesicular (VGLUT). Se han clonado al menos tres isoformas de VGLUT, que son de gran eficacia para modular la neurotransmisión glutamatérgica [51]. El estímulo nervioso hace que la neurona presináptica libere GLU, al fusionarse las vesículas que lo contienen con la membrana plasmática. El GLU liberado estimula a varios receptores pre y postsinápticos, para posteriormente ser recaptado por las neuronas presinápticas y sobre todo por los astrocitos, mediante los transportadores de aminoácidos excitatorios (EAAT1 y EAAT2). Dentro de los astrocitos, el GLU recaptado es convertido en glutamina, por la enzima glutamina-sintetasa. La glutamina pasa desde el astrocito a la neurona presináptica, donde se utiliza para sintetizar nuevo GLU, cerrándose el ciclo [52-53].

En la hendidura sináptica, el GLU liberado se une a dos tipos de receptores glutamatérgicos: ionotrópicos y metabotrópicos. Los receptores glutamatérgicos ionotrópicos son NMDA (N-metil-Daspartato), AMPA (amino-3-hidroxi-5-metil-4-isoxazolpropano) y kainato. Estos receptores ionotrópicos controlan canales iónicos permeables a cationes (sodio $[\mathrm{Na}+]$ y calcio $[\mathrm{Ca} 2+]$ ) y su activación provoca la despolarización de la neurona y/o activan vías de transducción o de señalización intracelular [54]. Por otra parte, existen tres grupos distintos de receptores metabotrópicos acoplados a proteínas G: Grupo I (Glum-1 y 5), que son postsinápticos y se acoplan a las subunidades Gq/G11, mientras que los del Grupo II (Glum-2 y 3) y Grupo III (Glum-4, 6, 7 y 8) son presinápticos y se acoplan a las subunidades Gi/Go [55].

Los R-NMDA son heterómeros con siete subunidades (NR1, NR2A-D y NR3A-B) que conforman un canal bloqueado, en reposo, por un átomo de magnesio. Para que el receptor NMDA sea funcional debe tener, al menos, una subunidad NR1 y una NR2. Los receptores NMDA son los únicos conocidos que requieren dos mecanismos distintos para ser activados. Por un parte, el GLU debe unirse a la subunidad NR2, mientras que la glicina, que se comporta como un modulador alostérico, se fija sobre la unidad NR1 [54]. Sin la presencia de ambos co-agonistas (glicina y GLU), el canal iónico no se abrirá. Pero, además, para que se abra el canal acoplado al receptor NMDA es necesaria una corriente eléctrica previa, que desplaza al magnesio que los obstruye. Esta corriente eléctrica es aportada por la activación de receptores AMPA (R-AMPA). Por tanto, la presencia de GLU y glicina sobre el RNMDA y la corriente despolarizadora previa aportada por el R-AMPA, permite la entrada de calcio, provocando la excitación neuronal durante períodos de tiempo más largos. Al igual que los R-AMPA, los receptores kainato están asociados con canales dependientes del voltaje que permiten la entrada de sodio, pero parecen estar en menor cantidad y con una distribución distinta a los R-AMPA en el SNC [15].

\subsubsection{Disfunción glutamatérgica en la depresión}

Muchos de los pasos comentados del funcionalismo glutamatérgico pueden encontrarse alterados en la depresión, así como en otras patologías mentales y neurológicas, y por ello pueden ser potenciales dianas terapéuticas. Algunas de estas alteraciones funcionales, tanto experimentales como clínicas, pueden estar sometidas a debate, pero, en cualquier caso, es una información a considerar.

\subsubsection{Alteraciones en las vesículas sinápticas y sus transportadores (GLUTv)}

Se ha demostrado que el estrés prenatal, así como otros tipos de estrés continuado, en roedores y también en humanos, afecta el desarrollo neurológico y cambia de forma permanente la estructura y la función del cerebro a lo largo de la vida. De hecho, el estrés prenatal puede inducir algunas alteraciones mentales compatibles con la depresión y la ansiedad [56]. 
Desde el punto de vista experimental, se ha observado que el transportador de GLU vesicular 1 (GLUT1v) desempeña un papel clave en la liberación y en la eficacia de la transmisión sináptica glutamatérgica. Así, en situaciones de estrés, los animales que genéticamente presentan una disminución de los niveles de GLUT1v, muestran signos experimentales de depresión, como indefensión o anhedonia, junto a un aumento de la síntesis neuronal de GLU, con disminución de GABA y del transportador de aminoácidos excitatorios (EAAT1) a nivel cortical e hipocampal. Es posible que el déficit del transportador vesicular GLUT1v sea un factor de riesgo biológico potencial para sufrir depresión [57]. La disminución de los transportadores GLUT1v, en los núcleos dorsales del rafe, se acompañó de una disminución del funcionalismo serotoninérgico en áreas del tronco cerebral e hipocampo, con menor proliferación neuronal y con una desensibilización de los autorreceptores 5-HT1A [58], junto a un descenso duradero de la neurotrofina BDNF. El patrón de expresión de estas proteínas afecta la plasticidad neuronal y la conectividad, lo que se manifiesta por rasgos conductuales asociados a la depresión. Otros autores han encontrado en ratas con depresión experimental por "indefensión aprendida" una disminución de este transportador GLUT1v, que aumenta en varios modelos experimentales con la administración de antidepresivos. Se postula que la reducción GLUT1v podría ser un mecanismo compensador para contrarrestar los mayores niveles de GLU sináptico [59]. En un estudio realizado en un número pequeño de individuos con depresión mayor y depresión bipolar, también se ha podido encontrar una disminución de GLUT1v en corteza entorrinal [60]. Por tanto, la disminución de GLUT1v puede conducir, a corto plazo, a una alteración del funcionalismo glutamatérgico que, mediante la modificación de la expresión de otras proteínas implicadas en la función glutamatérgica, podría alterar los niveles de BDNF y la función serotoninérgica que, como es sabido, están relacionadas con el comportamiento depresivo y con el mecanismo de acción de algunos antidepresivos [61].

Por otra parte, es destacable que la desipramina y la fluoxetina, así como otros agentes con actividad antidepresiva, como la clozapina y el litio, un estabilizador del humor, aumentaron la expresión del ARNm GLUT1v en las neuronas de la corteza cerebral y el hipocampo, aumentando la expresión de los transportadores de GLUT1v en sus zonas de proyección. Por tanto, puesto que en la depresión experimental y en algunos pacientes con depresión, parece existir un déficit de GLUT1v y la administración de agentes con propiedades antidepresivas recuperan estos transportadores, se postula que los GLUT1v podrían ser una diana y un marcador útil de actividad antidepresiva. Además, los cambios adaptativos en GLUT1v podrían constituir un punto de encuentro en el mecanismo de acción de agentes con estructuras químicas y grupos terapéuticos muy diferentes, pero dotados todos de propiedades antidepresivas [62].

\subsubsection{Alteraciones en la maquinaria de liberación presináptica de neurotransmisores}

La liberación del neurotransmisor es un proceso facilitado por un complejo proteico denominado SNARE (soluble N-ethylmaleimide sensitive factor attachment protein receptor), que permite la fusión de las vesículas que contienen el neurotransmisor con la membrana neuronal. Los descubridores de estas proteínas y de su función fueron reconocidos con el Premio Nobel de Medicina en 2013 (Randy Schekman, James Rothman y Thomas Südhof). El complejo SNARE está formado por varias proteínas, entre las que destacan funcionalmente la sintaxina-1, SNAP-25 (synaptosomal-associated protein 25) y la sinaptobrevina (vesicle-associated membrane protein o VAMP). El proceso de liberación es calcio dependiente y se produce por la dilución de la membrana vesicular con la neuronal, gracias a las proteínas SNARE [63]. El complejo SNARE es de tal importancia que las alteraciones del mismo se conocen con el término de "sinaptopatías" y pueden estar relacionadas con algunos síntomas presentes en la depresión y en otros trastornos psiquiátricos [64].

Estudios genéticos en humanos relacionan algunos polimorfismos de nucleótidos únicos (SNP) de la SNAP-25, en zonas del hipocampo pacientes con depresión mayor [64-65], asó como alteraciones de la SNAP-25 en el complejo SNARE de sujetos con depresión mayor que se habían suicidado [66].

En el modelo de depresión provocado por el estrés prenatal en ratas se presentan alteraciones del comportamiento, características de la depresión experimental, que se asocian con aumentos en el complejo SNARE (SNAP-25, sintaxina-1 y VAMP2) y en el GLUT1v, tanto en el hipocampo como en 
corteza prefrontal. Estas alteraciones aumentan la liberación de GLU por lo que se produce un efecto neurotóxico, que explicaría la ansiedad y el déficit cognitivo característico de la depresión [56].

Algunos antidepresivos, inhiben la formación del complejo SNARE, contrarrestando la acción del estrés [56], por lo que reducen significativamente la liberación de GLU [67]. Por tanto, el complejo SNARE parece ser una diana fisiopatológica para el tratamiento de la depresión [56]. Otros estudios han demostrado que la fluoxetina disminuyó en casi un 50\% la SNAP-25, a la vez que disminuyó la entrada presináptica de calcio, por lo que disminuye la función del complejo SNARE y por tanto la exocitosis del GLU desde la vesícula sináptica [68].

\subsubsection{Alteraciones en los mecanismos de recaptación del GLU}

La recaptación del GLU es un proceso dinámico y complejo. Mantener los niveles sinápticos adecuados de GLU ("ni mucho, ni poco") es vital para el SNC. Para ello, el GLU liberado es recaptado por una serie de transportadores activos de alta eficiencia, siendo el principal mecanismo finalizador de su acción sobre los receptores. Los transportadores de aminoácidos excitatorios, denominados EAAT, se encuentran tanto en las membranas de las neuronas presinápticas y en las células gliales. Los EAAT1 y EAAT2 se expresan principalmente en células gliales, siendo el EAAT2 predominante en el cerebro y responsable de más del $90 \%$ del GLU recaptado, por lo que evita su acumulación y la excitotoxicidad. Múltiples mecanismos genéticos, epigenéticos, ambientales, entre otros pueden alterar la función de estos transportadores [69]. Se ha descrito una disminución de los genes de EAAT2 y EAAT1 y de su ARNm, en la corteza prefrontal anterior y dorsolateral y en el locus coeruleus de pacientes con depresión mayor [70]. Además, el estrés prenatal disminuye la expresión de ARNm del EAAT2 en el hipocampo, núcleo estriado y corteza frontal y del EAAT3 en el hipocampo de ratas. Por tanto, un déficit de los transportadores de GLU genera un aumento sináptico y extrasináptico de GLU que provoca neurotoxicidad y alteración de la plasticidad sináptica, fenómenos relacionados con la fisiopatología del trastorno de depresivo [71].

Por el contrario, los agentes que estimulan los EAAT aumentan la recaptación y limpian la sinapsis de GLU. Estos agentes tienen propiedades antidepresivas. La disminución experimental por estrés de la expresión de transportadores glutamatérgicos gliales en el hipocampo es revertida por el tratamiento crónico con fluoxetina [72]. Asimismo, se ha podido demostrar que la tianeptina, un antidepresivo considerado con un mecanismo de acción atípico [10], normaliza los niveles de GLU inducidos por el estrés crónico experimental, gracias a un aumento de la expresión de los transportadores gliales [73]. En este sentido, se postula que la acción antidepresiva del riluzol se debe a su capacidad para aumentar la recaptación de GLU, reduciendo la presencia del aminoácido excitatorio a nivel extracelular [74]. La ketamina, que ha demostrado poseer propiedades antidepresivas de inicio rápido, provoca también un aumento de la expresión de transportadores EAAT, con lo que incrementa la recaptación de GLU [75]. Estos datos, obtenidos de estudios postmortem en deprimidos y en depresión experimental, indican que la reducción de transportadores de GLU se asocia a la depresión, mientras que la normalización de la función de los EAAT estaría involucrada en la actividad terapéutica de, al menos, algunos antidepresivos.

\subsubsection{Alteraciones en los niveles de GLU extracelular}

No existe una asociación simple entre los niveles de GLU y los trastornos del estado de ánimo, debido a la complejidad del funcionalismo glutamatérgico, a las variantes metodológicas entre estudios, a los subtipos de depresión, a la variabilidad de las muestras de pacientes, por ejemplo, suicidas vs. deprimidos sin suicidio, a la frecuente comorbilidad, a las regiones cerebrales evaluadas, así como los posibles efectos de los agentes psicoterapéuticos que los pacientes están recibiendo [74].

En diversos modelos acreditados de depresión experimental se produce un aumento de los niveles de GLU, en zonas cerebrales relacionadas con la fisiopatología de la depresión, como el hipotálamo y la corteza frontal. En estos modelos, el estrés activa los receptores de glucocorticoides neuronales, lo que aumenta los niveles extracelulares de GLU que estimulan los receptores NMDA, tanto las neuronas como en los astrocitos, lo que provoca neurodegeneración [76]. 
Sin embargo, los estudios en humanos son menos concluyentes. Se han determinado resultados contradictorios en los niveles de Glx (la suma de niveles de GLU y glutamina) en el LCR de pacientes con depresión. En un estudio se encontró un aumento de glutamina [77], mientras que en otro estudio los niveles de GLU disminuyeron en pacientes con depresión [78], en otros se encontraron diferencias en los niveles de Glx en el LCR de pacientes con depresión, respecto a los controles [52,79].

No obstante, algunos autores señalan que, en la mayoría de estudios, los pacientes deprimidos parecen tener un aumento de la actividad glutamatérgica basal [80]. En un meta-análisis de 12 estudios, los niveles de GLU en sangre periférica estaban elevados en los pacientes deprimidos [81]. Un estudio más reciente, no incluido en este meta-análisis, detectó niveles de Glx elevados en pacientes de edad avanzada con depresión mayor respecto a los controles, lo que podría explicar que, los procesos neurodegenerativos y la pérdida de memoria en los sujetos mayores estén relacionados con niveles elevados de GLU [82]. Sin embargo, un meta-análisis más reciente [83] muestra que los niveles de Glx se encontraban disminuidos en la CPFm de pacientes con depresión en comparación con los controles, aunque no se encontraron diferencias significativas en los niveles de GLU o glutamina entre los dos grupos. En los pacientes tratados con antidepresivos, los niveles de Glx fueron más bajos en CPFm vs. los controles y no se encontraron diferencias entre pacientes no medicados con depresión y controles sanos. Pese a la discordancia de datos, la existencia de una disfunción glutamatérgica en la depresión parece demostrada.

\subsubsection{Disfunción a nivel de receptores glutamatérgicos}

Los receptores glutamatérgicos, tanto ionotrópicos como metabotrópicos, juegan un papel fundamental en el funcionalismo glutamatérgico. Alteraciones de estos receptores han sido implicadas en la fisiopatología de diversos trastornos mentales y neurológicos y, entre ellos, en la fisiopatología de la depresión. Además, los receptores glutamatérgicos constituyen unas dianas antidepresivas de gran trascendencia de futuro, que empiezan a desvelarse en el tratamiento actual de la depresión resistente y en los pacientes con tendencias intensas de intentos de suicidio.

\subsection{Disfunción a nivel de receptores glutamatérgicos metabotrópicos}

Entre los receptores metabotrópicos relacionados, tanto fisiopatológica como terapéuticamente con la depresión, los más estudiados han sido los R-Glum-2/3 [84] y el R-Glum5 [85]. Se ha demostrado un aumento de los R-Glum-2/3 en corteza prefrontal de pacientes con depresión. Este aumento no parece deberse a la exposición de antidepresivos, ya que la fluoxetina no modifica la densidad de estos receptores. Además, los antagonistas de los R-Glum2/3, MGS0039 y LY341495, muestran actividad antidepresiva experimental [84]. De momento, se desconoce su utilidad clínica.

Los receptores Glum5 se encuentran a nivel postsináptico y en las células gliales de la sinapsis tripartita, en especial en el hipocampo, núcleos caudado y putamen, corteza cerebral y tálamo. En modelos de depresión experimental, se observa una menor densidad de estos receptores R-Glum5 por lo que se ha implicado en la fisiopatología de la depresión [86]. Asimismo, los ratones carentes de este receptor (R-Glum5 $\mathrm{KO}$ ) muestran un comportamiento depresivo. El tratamiento antidepresivo crónico, aumentó la expresión de los R-Glum5, lo que parece indicar que la regulación de estos receptores puede participar en los efectos terapéuticos de los antidepresivos [87].

Desde el punto de vista clínico, los datos son poco comparables, debido a las diferencias metodológicas de los estudios. No obstante, se ha detectado una disminución de los R-Glum5 [88], también en neuroimagen, en corteza prefrontal de pacientes deprimidos [89]. Además, Deschwanden et al. [90] encontraron una disminución del $10 \%$ al $20 \%$ de R-Glum 5 en varias regiones cerebrales, incluyendo el tálamo y la corteza cingulada anterior (ACC), de pacientes con depresión. Sin embargo, en un estudio más reciente, no se observaron diferencias significativas en la densidad ni en la distribución de R-Glum5 en relación con los controles sanos [87]. En modelos experimentales de depresión, algunos moduladores alostéricos de estos R-Glum5 (AZD2066; Basimglurant) muestran eficacia, hecho que no se ha observado en clínica [91]. Por tanto, los receptores metabotrópicos 
glutamatérgicos podrían ser posibles dianas para el descubrimiento de nuevos medicamentos antidepresivos [92], que aún no han demostrado eficacia clínica.

\subsection{Disfunción a nivel de receptores glutamatérgicos ionotrópicos}

Los receptores glutamatérgicos ionotrópicos parecen estar más relacionados con los mecanismos fisiopatológicos y sobre todo terapéuticos de la depresión. Así, en un modelo de ratas deprimidas (FSL) se ha podido demostrar una disfunción que afecta a distintas subunidades de R-AMPA y RNMDA. En esta cepa de ratas FSL, a nivel del hipocampo, se detectó una menor proporción de subunidades GluN2A del R-NMDA y de subunidades GluA2/GluA3 del receptor AMPA [93].

De momento, la evaluación in vivo de los receptores ionotrópicos en humanos no es posible. Sin embargo, en estudios postmortem de corteza prefrontal de pacientes con depresión y suicidio, se observó que varios de genes de las subunidades de los R-NMDA y de los R-AMPA tenían una mayor expresión en las mujeres con depresión. Los autores postulan que el ARNm de la subunidad GluN2B de los R-NMDA podría ser un marcador de potencialidad suicida en mujeres deprimidas [94].

Los receptores NMDA tienen una clara relación fisiopatológica y terapéutica con la depresión. Así, la encefalitis provocada por anticuerpos anti R-NMDA se caracteriza por un trastorno depresivo mayor [95]. Además, en estudios postmortem de pacientes deprimidos, se ha podido detectar un aumento significativo de la subunidad NR2C de R-NMDA en el locus coeruleus [88] y una reducción de las subunidades NR2A (54\%) y NR2B (48\%) del receptor NMDA en corteza prefrontal [84], junto a un aumento de la subunidad NR2A en la amígdala de los sujetos deprimidos vs. controles [96]. Asimismo, se ha podido comprobar que en la depresión relacionada con procesos inflamatorios está implicada la subunidad NR2 del R-NMDA [97]. Se ha sugerido que la liberación excesiva de GLU hiperactiva los receptores NMDA, sobre todo los extrasinápticos, lo que se traduce por neurotoxicidad y neurodegeneración. En la depresión, La neurotoxicidad se manifiesta clínicamente por una atrofia neuronal acompañada de reducciones del volumen de determinadas zonas cerebrales [98] y en el número y densidad de células gliales [7].

Además, la observación de que los antagonistas de los R-NMDA, especialmente la ketamina, hayan demostrado una acción antidepresiva destacable es la pista más importante que implica a estos receptores con la hipótesis glutamatérgica de la depresión [99].

Por otra parte, los datos sobre la posible participación del R-AMPA en la fisiopatología de la depresión son más escasos, pero no menos importantes. De hecho, los estudios experimentales sugieren que el R-AMPA y el R-NMDA trabajan conjuntamente y existen evidencias que implican un papel preponderante del funcionalismo de los R-AMPA, tanto en la fisiopatología como en la terapéutica de la depresión. Es muy destacable que todos los potenciadores del R-AMPA estudiados muestren eficacia en todos los modelos experimentales de depresión [100]. De hecho, un neuropéptido endógeno, la cicloprolilglicina, es un modulador positivo del R-AMPA, que es capaz de aumentar el contenido de BDNF en las neuronas y ha demostrado efecto antidepresivo experimental en la rata. La cicloprolilglicina podría participar en la regulación fisiológica del estado de ánimo [101]. Además, diversos estudios conductuales, celulares y moleculares realizados con ketamina apoyan la teoría de que un aumento de la actividad del R-AMPA, que induce un aumento de la plasticidad sináptica, es fundamental para su efecto antidepresivo [91].

En el modelo de depresión inducido por estrés crónico en la rata, se producen cambios morfológicos, como hipertrofia dendrítica, y moleculares, alteración de la relación entre subunidades GluR1 y GluR2 de los R-AMPA en las neuronas de la amígdala basolateral. Estos cambios pueden prevenirse con la administración previa de fluoxetina, lo que indica que los R-AMPA podrían estar implicados en aspectos fisiopatológicos y terapéuticos de la depresión provocada por el estrés [102].

En ratones con supresión genética de la subunidad principal del R-AMPA (GluR-A) se obtiene un modelo de depresión con disminución de los niveles de 5-HT y NA y aumento de GLU y RNMDA. Este modelo experimental, apoya la hipótesis que señala que los compuestos que aumentan la señalización del R-AMPA o disminuyen las funciones del R-NMDA tienen efectos antidepresivos [103]. Algunos antidepresivos en tratamiento crónico, como la fluoxetina (ISRS) y la reboxetina 
(ISRN) [104] o la tianeptina [10,105], aumentan la densidad de R-AMPA, poniendo de manifiesto la importancia de este receptor en la terapéutica de la depresión.

En clínica, en estudios con ligandos marcados (binding), se ha detectado un aumento de RAMPA (>20\%) selectivo en la corteza cingulada anterior de pacientes con depresión, no observable en otras áreas cerebrales [100] [106]. En estudios postmortem de pacientes con depresión, se ha señalado una reducción en los niveles de ARNm de las subunidades GRIA1-3 de R-AMPA en la zona CA1 y giro dentado, pero no en el núcleo estriado [107]. No está claro si estos cambios son consecuencia o causa fisiopatológica en la depresión. Sin embargo, es posible que la reducción de las subunidades del R-AMPA sean la base de las alteraciones de la plasticidad sináptica observada en la depresión [106].

\section{Regulación funcional no aminérgica. Resultados en clínica antidepresiva en humanos.}

Como hemos comentado, los mecanismos fisiopatológicos que no abordan de forma directa los sistemas monoaminérgicos son múltiples. Muchos de ellos constituyen dianas fisiopatológicas para el hallazgo de nuevos antidepresivos. Sin embargo, pese a los múltiples esfuerzos de investigación, los resultados no son siempre los deseados. En este apartado nos centraremos exclusivamente en aquellos mecanismos implicados en la depresión que han tenido una traducción clínica y terapéutica para el tratamiento de esta importante patología mental. Básicamente tenemos resultados con el abordaje del funcionalismo gabérgico y glutamatérgico.

Una de las dianas que han dado resultados terapéuticos en la depresión es la del funcionalismo gabérgico, si bien no a través de las benzodiazepinas, uno de los grupos terapéuticos más utilizados, que actuarían como moduladores alostéricos de los receptores GABA-A. También se han explorado fármacos antagonistas de los receptores GABA-B [108].

Los fármacos que afectan al sistema de neurotransmisores glutamatérgico han recibido una especial atención. Este sistema participa en funciones fundamentales, como la regulación de la plasticidad sináptica y además tienen un importante impacto en procesos esenciales del estado de ánimo, como la cognición y las recompensas. Se han desarrollado programas de investigación de fármacos que abordan el sistema glutamatérgico con agentes que afectan a los receptores ionotrópicos NMDA y AMPA, receptores metabotrópicos, así como a transportadores glutamatérgicos situados en las células gliales e inhibidores de la liberación de GLU [109].

\subsection{Dianas gabérgicas con fármacos aprobados para el tratamiento de la depresión}

Es conocido que algunos tipos de neuronas, como las glutamatérgicas y las gabérgicas, son capaces de sintetizar neuroesteroides que modulan la excitabilidad neuronal. Entre estos destaca la alopregnanolona, con efectos sedantes y anestésicos, así como con capacidad de regular el estado de ánimo. Este neuroesteroide es un modulador alostérico del receptor GABA-A y del eje HHA. En pacientes con diversos trastornos depresivos existen niveles más bajos de alopregnanolona en el LCR. Además, diversos antidepresivos, ISRS, ADT y la mirtazapina aumentan los niveles de alopregnanolona [110]. En marzo de 2019, la alopregnanolona sintética (Brexanolone ${ }^{\circledR}$ ) ha sido el primer medicamento aprobado por la FDA, para el tratamiento de la depresión postparto [111].

La alopregnanolona es un metabolito importante de la progesterona que aumenta durante el embarazo. La alopregnanolona es un potente esteroide endógeno que disminuye la excitabilidad neuronal a través de la modulación alostérica positiva de los receptores GABA-A sinápticos y extrasinápticos. Los receptores GABA-A extrasinápticos producen una inhibición tónica, lo que diferencia a este esteroide de las benzodiazepinas que producen una inhibición fásica en los receptores GABA-A [112]. Además, deben existir otros mecanismos que expliquen que el efecto antidepresivo de alopregnanolona dure, al menos un mes, tras la interrupción del tratamiento [113].

La única indicación aprobada de la alopregnanolona es la depresión posparto, un cuadro grave y una de las principales causas de morbi-mortalidad materna, que afecta al bienestar cognitivo, conductual, emocional y físico de la madre, del bebé y de su familia. La administración de alopregnanolona se realiza por perfusión intravenosa continua, durante un período total de 60 horas, 
bajo monitorización médica [114]. En estas condiciones, ha demostrado eficacia clínica en mujeres con depresión grave posparto en un estudio abierto [115] y en un ensayo doble ciego, aleatorizado, controlado con placebo [116], así como en dos estudios multicéntricos, doble ciego frente a placebo, en fase III [117]. La respuesta antidepresiva se mantuvo durante los 30 días estudiados. Alopregnanolona fue bien tolerada, siendo los eventos adversos más frecuentes las cefaleas, mareos y somnolencia [39,113]. Por tanto, alopregnanolona presenta un inicio rápido de acción en la depresión postparto, pero se desconoce si el efecto se mantiene más allá del mes, ya que la última valoración realizada en los ensayos clínicos fue solo hasta los 30 días [118].

\subsection{Dianas glutamatérgicas con fármacos aprobados para el tratamiento de la depresión}

Como hemos comentado, casi todos los pasos del funcionalismo glutamatérgicos están implicados, de forma muy importante, en la fisiopatología psiquiátrica y especialmente en la patogenia de la depresión. Por tanto, no es de extrañar que los distintos elementos del sistema glutamatérgico sean dianas farmacológicas, con distinto nivel de éxito, para el tratamiento de la depresión. En este apartado comentaremos las estrategias farmacológicas que han dado resultados clínicos que han permitido la entrada de algunos medicamentos en el arsenal antidepresivo. Algunos de ellos ya tenían un papel en terapéutica en otras indicaciones, pero sus posibles propiedades antidepresivas permiten su uso antidepresivo como tratamiento compasivo.

\subsubsection{Potenciador de la recaptación de GLU e inhibidor de la liberación presináptica: Riluzol}

El riluzol es un fármaco que está aprobado para el tratamiento de la esclerosis lateral amiotrófica (ELA) y que aumenta la actividad del transportador EAAT-2 de los astrocitos, por lo que potencia la recaptación de GLU, a la vez que inhibe su liberación presináptica. La resultante es una disminución importante de la tasa de GLU en la hendidura sináptica y en su entorno extrasináptico. Como consecuencia, las acciones del riluzol son equivalentes a las que se consiguen con los antagonistas de los receptores glutamatérgicos no selectivos, al no estimularse ni los receptores glutamatérgicos ionotrópicos (R-NMDA, R-AMPA y R-kainato), ni los metabotrópicos (R-Glum1-8) [119].

El perfil glutamatérgico de riluzol estimuló su estudio en el tratamiento de la depresión mayor, primero en un estudio abierto, en pacientes resistentes al tratamiento antidepresivo, siendo eficaz linealmente a partir de las 3 semanas hasta la sexta semana, respecto a la basal, ya que no se incluyó un grupo con placebo [120]. Resultados similares se obtuvieron, en otro pequeño estudio abierto de 10 pacientes, empleando el riluzol (100 mg/día) como coadyuvante de otros antidepresivos [121]. Los resultados controlados son controvertidos; en dos estudios riluzol no fue superior al placebo en prevención de recaídas, en pacientes que respondían a una única perfusión de ketamina, ni tampoco en los que no respondieron a este agente [122]. En una reciente revisión sistemática y meta-análisis, que incluyó 373 pacientes de 7 ensayos aleatorizados controlados con placebo, no se pudo demostrar la superioridad de riluzol sobre el placebo. Sin embargo, riluzol potenció el efecto antidepresivo cuando se asoció al citalopram [123]. En general, el riluzol fue bien tolerado en estos estudios y no se observaron efectos psicotomiméticos [124]. Su empleo antidepresivo es compasivo y parece que su eficacia se manifiesta en asociación con otros antidepresivos.

\subsubsection{Antagonistas y moduladores de los receptores NMDA como antidepresivos}

El canal iónico controlado por el receptor NMDA es sumamente complejo y su complejidad lo convierte en una diana muy prolífera en la búsqueda de nuevos antidepresivos. Así, existen agentes farmacológicos que actúan directamente sobre los distintos componentes del complejo receptorial NMDA, entre los que se encuentran, como representantes más característicos, el rapastinel, el apimostinel y la ketamina, mientras que otros lo hacen de forma indirecta, al sustraer el GLU de la hendidura sináptica, como sería el caso del ya comentado riluzol. Existe un amplio plantel de agentes moduladores de los R-NMDA, con propiedades antidepresivas experimentales e incluso clínicas. Sin embargo, el estricto desarrollo clínico requerido por las agencias del medicamento hace que muchos de estos agentes no consigan su aprobación como antidepresivos. 
4.2.2.1. Moduladores de receptores glutamatérgicos con desarrollo clínico sin éxito como antidepresivos

El rapastinel, un polipéptido con actividad como agonista parcial sobre el locus de la glicina del R-NMDA, demostró, en estudios de fase II, resultados positivos frente a placebo en pacientes que no habían respondido al menos a un antidepresivo. Estos datos hicieron que se consiguiera la designación "Fast Track" por la FDA, lo que permite un desarrollo más rápido del producto, para el tratamiento de la depresión [39]. Sin embargo, en tres estudios en fase III, rapastinel no se diferenció del placebo en las variables claves del efecto antidepresivo, por lo que el fármaco ha sido discontinuado [125]. De nuevo, se pone de manifiesto la dificultad de modular el sistema glutamatérgico como diana terapéutica, especialmente para el tratamiento de patologías mentales.

Lanicemina es un antagonista R-NMDA de baja afinidad que, en administración intravenosa, presentó un éxito inicial en pacientes con depresión resistente. Sin embargo, en estudios posteriores lanicemina no se diferenció del placebo [126]. Recientemente, el BHV-5000 que tiene como metabolito activo a la lanicemina, se encuentra en desarrollo como antidepresivo [122].

Otros agentes con afinidad por los R-NMDA son el traxoprodil, EVT-101, rislenemdaz, apimostinel, AGN-241751, AV-101 y NRX-101/NRX-100. Algunos de ellos no han pasado los filtros de los ensayos clínicos y otros se encuentran en fases precoces de desarrollo [122]. No obstante, el amplio número de agentes encaminados a explotar la diana del R-NMDA, parece indicar el interés que este receptor tiene como diana farmacológica en la terapia de la depresión.

\subsubsection{Ketamina como modulador glutamatérgico: de anestésico a antidepresivo de acción rápida}

La ketamina es un derivado de la fenciclidina y se emplea como anestésico disociativo desde el año 1970. La ketamina es una mezcla racémica de (S)- y (R)-ketamina, con afinidad para diferentes subtipos de R-NMDA. La ketamina tiene un amplio espectro de acciones farmacológicas, incluyendo un efecto disociativo, analgésico y sedativo, además de generar catalepsia y broncodilatación. Aunque la ketamina es conocida clásicamente por sus propiedades anestésicas y alucinatorias, investigaciones recientes han descubierto nuevas propiedades, incluyendo un efecto neuroprotector, antinflamatorio, cierto efecto antitumoral, anticonvulsivo, así como un efecto analgésico en dolor crónico y en cefaleas [127]. En la actualidad, se están realizando unos 800 ensayos clínicos que exploran diversos usos no anestésicos de la ketamina. Además, ketamina presenta un efecto antidepresivo rápido, que ha hecho que su empleo "off-label" (sin indicación aprobada oficialmente) en la clínica antidepresiva se haya disparado mundialmente [128-129].

El espectro de actividad de la ketamina no se limita a sus propiedades terapéuticas, ya que tiene también un amplio perfil de efectos secundarios, entre los que se encuentra su conocido potencial de abuso ("Special $\mathrm{K}^{\prime}$ ), debido a sus efectos euforizantes, que la ha convertido en una droga recreativa popular e ilícita consumida en todo el mundo, lo que la ha relegado en favor de otros agentes [130]. Además, ketamina puede provocar taquicardia sinusal, efectos neuropsiquiátricos, dolor abdominal, daño hepático y lesiones urogenitales que, con dosis altas, puede llegar a cistitis ulcerosa [129].

Sus propiedades farmacológicas, su aportación a la fisiopatología de la depresión y el hecho de ser el pionero de los antidepresivos de rápida acción, es el motivo por el que la incluimos en este apartado.

En relación con el mecanismo de acción antidepresivo de ketamina, al igual que sucede con muchos otros psicofármacos, hemos de señalar que se encuentra sometido a un amplio debate. La ketamina es un antagonista no competitivo y no selectivo de las subunidades GluN2 del R-NMDA glutamatérgico, que se une al sitio de unión (locus) de la fenciclidina, situado en el interior del canal iónico del receptor NMDA, bloqueando el canal de una forma similar a cómo lo hace el ion de magnesio (Mg++). Puesto que la ketamina es un antagonista del R-NMDA, se podría deducir que se produciría, tras su administración, una reducción de la transmisión excitatoria glutamatérgica. Sin embargo, estudios de neuroimagen en humanos, determinaciones de GLU extracelular en corteza prefrontal y estudios electrofisiológicos en roedores, ponen de manifiesto que el antagonismo de los R-NMDA se asoció con un aumento importante de la actividad cortical en humanos, incremento del 
GLU en corteza prefrontal de ratas y aumento de la actividad electrofisiológica en roedores. Estos efectos paradójicos relacionados con la elevación del GLU extracelular después del antagonismo del R-NMDA dio lugar a la llamada "hipótesis de desinhibición" [131].

Según esta hipótesis, la ketamina, a dosis subanestésicas, bloquea selectivamente los R-NMDA del soma de las interneuronas inhibidoras gabérgicas, por lo que éstas no liberarían GABA y dejarían de frenar a las neuronas piramidales, que responderían con una descarga y el aumento de GLU extracelular. Se ha podido confirmar que la ketamina, a dosis subanestésicas, disminuye la inhibición en las neuronas piramidales, lo que provoca un aumento del impulso excitatorio de éstas sobre el hipocampo [132]. La selectividad de ketamina por los R-NMDA de las interneuronas gabérgicas se debe a que éstos son de disparo rápido, por lo que expulsan al $\mathrm{Mg++}$ del canal del R-NMDA, permitiendo la entrada de ketamina, que bloquea dicho canal. Por tanto, la ketamina inhibe las interneuronas inhibidoras gabérgicas, lo que permite el disparo de las neuronas piramidales glutamatérgicas. Este sería el mecanismo inicial agudo del efecto antidepresivo de la ketamina [131].

Sin embargo, las neuronas gabérgicas no son homogéneas, existiendo además una subpoblación importante (aproximadamente un $20 \%$ en corteza prefrontal de roedores) que expresan somatostatina, denominadas interneuronas SST, que se dirigen selectivamente, no a los cuerpos, sino a las dendritas apicales de las neuronas piramidales y controlan la integración dendrítica [133]. Se ha demostrado que la ketamina, además de inhibir las interneuronas gabérgicas de disparo rápido, suprime la actividad de las interneuronas SST en la corteza prefrontal medial, por lo que se produce una desinhibición dendrítica que aumenta la entrada de calcio sináptico en las espinas dendríticas apicales de las neuronas piramidales. Este incremento de calcio puede contribuir a aumentar la plasticidad sináptica y restaurar la coordinación de la actividad de los circuitos neuronales en la corteza prefrontal, que podrían estar alterados por eventos, como el estrés, presentes en la depresión [134]. Este mecanismo sería complementario de la hipótesis de la desinhibición, ya que, a través de las interneuronas gabérgicas de disparo rápido y de las interneuronas SST, se conseguiría una estimulación de las neuronas piramidales corticales y de la transmisión glutamatérgica.

La inhibición directa de los R-NMDA por la ketamina se ha considerado, durante varios lustros, como el mecanismo inicial responsable de su actividad antidepresiva. Sin embargo, otros antagonistas de los R-NMDA, como el MK-801, que se une al mismo locus que la ketamina, carece de efectos antidepresivos sostenidos. Otros antagonistas NMDA, como memantina, el AZD6765 y el CP101606 , son poco eficaces como antidepresivos. Por lo tanto, la ketamina, así como sus enantiómeros, son los únicos antagonistas de R-NMDA que han demostrado eficacia antidepresiva en estudios clínicos controlados. De esta forma, la hipótesis que apunta que el bloqueo R-NMDA es responsable de la eficacia clínica de la ketamina se queda corta y es parcialmente cuestionable [135].

En efecto, las acciones antidepresivas de la ketamina pueden ser independientes de la inhibición de los R-NMDA. Los dos isómeros de la ketamina, (R)- y (S)-ketamina, tienen comportamientos muy diferentes sobre estos receptores. Así, la (S)-ketamina presenta cuatro veces más afinidad y capacidad de inhibición del R-NMDA que la (R)-ketamina, por lo que la (S)-ketamina es mucho más potente como anestésico que la (R)-ketamina. En roedores, la (R)-ketamina tiene mayor potencia antidepresiva que la (S)-ketamina, lo que sugiere que las acciones antidepresivas de la ketamina, en roedores, no se deben exclusivamente a su capacidad de inhibición de los R-NMDA [136].

Se han explorado otros mecanismos alternativos y complementarios al antagonismo de RNMDA [135] y cada vez existen más datos que avalan un papel más importante de los R-AMPA en la fisiopatología y el tratamiento de la depresión. Por un lado, la existencia de una alta densidad de receptores AMPA en estructuras responsables de la regulación del humor, como la corteza prefrontal y el hipocampo. Por otra, los moduladores positivos de los receptores AMPA se comportan como antidepresivos experimentales, con una eficacia comparable a la de los ADT o ISRS. Además, los RAMPA intervienen en la mayoría de los procesos de transmisión rápida y parecen ser un mecanismo central en la plasticidad sináptica [10]. Por ello, una hipótesis alternativa al antagonismo de RNMDA, aunque también puede considerarse complementaria, sería la que implica a los R-AMPA en el mecanismo de la acción antidepresiva de la ketamina. En este sentido, el bloqueo preferencial de los R-NMDA de las interneuronas gabérgicas provoca la desinhibición de las células piramidales y 
se produce una oleada de liberación de GLU, que estimularía fundamentalmente a los R-AMPA, ya que los R-NMDA estarían bloqueados por la ketamina. El estímulo de R-AMPA facilitaría la liberación de BDNF y la activación de otras vías de transducción, por ejemplo, la mTOR, que facilitarían la sinaptogénesis [137]. De hecho, la activación de los R-AMPA y el antagonismo de los R-NMDA parecen necesarias en la potenciación y plasticidad sináptica implicadas en las acciones antidepresivas de la ketamina [138].

La implicación de R-AMPA en los efectos antidepresivos de la ketamina tiene un amplio soporte experimental. Estudios electroencefalográficos en humanos y roedores, muestran un aumento de la potencia de la banda gamma, que se considera como una medida de desinhibición cortical, producida por la activación de receptores excitatorios ionotrópicos rápidos, entre los que se encuentran los RAMPA [139]. Además, la administración de dosis subanestésicas de ketamina facilita la transmisión sináptica mediada por R-AMPA en neuronas piramidales CA3 de la corteza prefrontal medial y del hipocampo. Por otra parte, estudios farmacológicos ponen de manifiesto que el pretratamiento con una dosis subumbral de un agonista R-AMPA (C-546) potencia los efectos antidepresivos experimentales de la ketamina. Por el contrario, el pretratamiento con el antagonista de R-AMPA (NBQX) bloqueó los efectos antidepresivos, en varios modelos experimentales, de la ketamina, sin afectar la actividad de los antidepresivos monoaminérgicos convencionales [140].

Por otra parte, en varios modelos experimentales, se ha demostrado que el tratamiento con ketamina produce una regulación al alza ("up-regulation") de los R-AMPA, en corteza prefrontal e hipocampo. Es de destacar que el aumento en el funcionalismo de los R-AMPA es paralelo a un mayor número de receptores en la superficie neuronal y no a una mayor apertura de sus canales, los cuales siempre mantienen el mismo ritmo. En este sentido, algunos ISRS, como la fluoxetina, y el ADT imipramina pueden producir una regulación al alza de los R-AMPA en el hipocampo o en corteza prefrontal medial. Asimismo, se ha demostrado que la tianeptina, un antidepresivo atípico, mediante la facilitación de la fosforilación de la subunidad GluA1 del R-AMPA, aumenta la eficacia del receptor al facilitar su presencia en la membrana neuronal [10]. Estos datos parecen indicar que la facilitación de la señalización mediada por R-AMPA podría representar un punto de convergencia en la acción antidepresiva de la ketamina y de los antidepresivos clásicos, ISRS y tianeptina [135].

Estos datos, junto con los comentados anteriormente, indican que la activación y regulación al alza de los R-AMPA, como consecuencia de la tormenta glutamatérgica provocada por el antagonismo R-NMDA en las interneuronas gabérgicas, son fundamentales en las acciones antidepresivas de la ketamina [140] y probablemente en la acción de otros antidepresivos [10].

Sin embargo, el mecanismo de acción antidepresivo de la ketamina no puede limitarse a su acción sobre receptores glutamatérgicos, ya sea mediante la inhibición directa de los R-NMDA o de forma indirecta por el aumento glutamatérgico sobre los R-AMPA. En definitiva, estos mecanismos receptoriales son solo interruptores que ponen en marcha mecanismos de transducción y vías de señalización que intentan restaurar las disrupciones fisiopatológicas de la depresión. Con técnicas de neuroimagen, se observa en la depresión una atrofia del hipocampo y de la corteza prefrontal medial, secundaria a la poda y contracción dendrítica de células piramidales, provocada por el estrés. Una restauración de estos daños es tarea de los antidepresivos y en concreto de la ketamina. De hecho, hay una amplia evidencia de que la ketamina, así como otros antidepresivos, activan numerosas vías de señalización que promueven la neurogénesis y la plasticidad sináptica [141].

Una de las vías de señalización diana de la ketamina es la vía de transducción BDNF-TrkB (tropomiosina relacionada con la cinasa B) (Figura 1). La BDNF, una neurotrofina sintetizada principalmente en las neuronas, que se distribuye ampliamente en el SNC, desempeña un papel fundamental para la supervivencia, diferenciación, crecimiento, desarrollo neuronal y plasticidad sináptica. Esta neurotrofina ejerce sus acciones al unirse a su receptor específico TrkB. En sujetos con depresión, se ha detectado una disminución de esta vía de señalización. El tratamiento antidepresivo provoca una regulación al alza de la vía BDNF-TrkB en la corteza prefrontal y el hipocampo, que se acompaña de una respuesta antidepresiva y un aumento de la resiliencia al estrés [140]. Los antidepresivos clásicos pueden incrementar los niveles de BDNF tras varias semanas de tratamiento, lo que coincide con su retraso en el inicio antidepresivo, mientras que la administración de ketamina 
aumenta rápidamente (30 minutos) los niveles de BDNF, lo que se asocia con un aumento de la neurogénesis hipocampal, y con los efectos antidepresivos rápidos y sostenidos producidos por la ketamina [142]. Además, la activación de la vía BDNF-TrkB por ketamina produjo una regulación del transportador EAAT-1 de los astrocitos, lo que frena los cambios morfológicos observados en el hipocampo de ratas con depresión experimental, a la vez que normaliza su comportamiento [143].

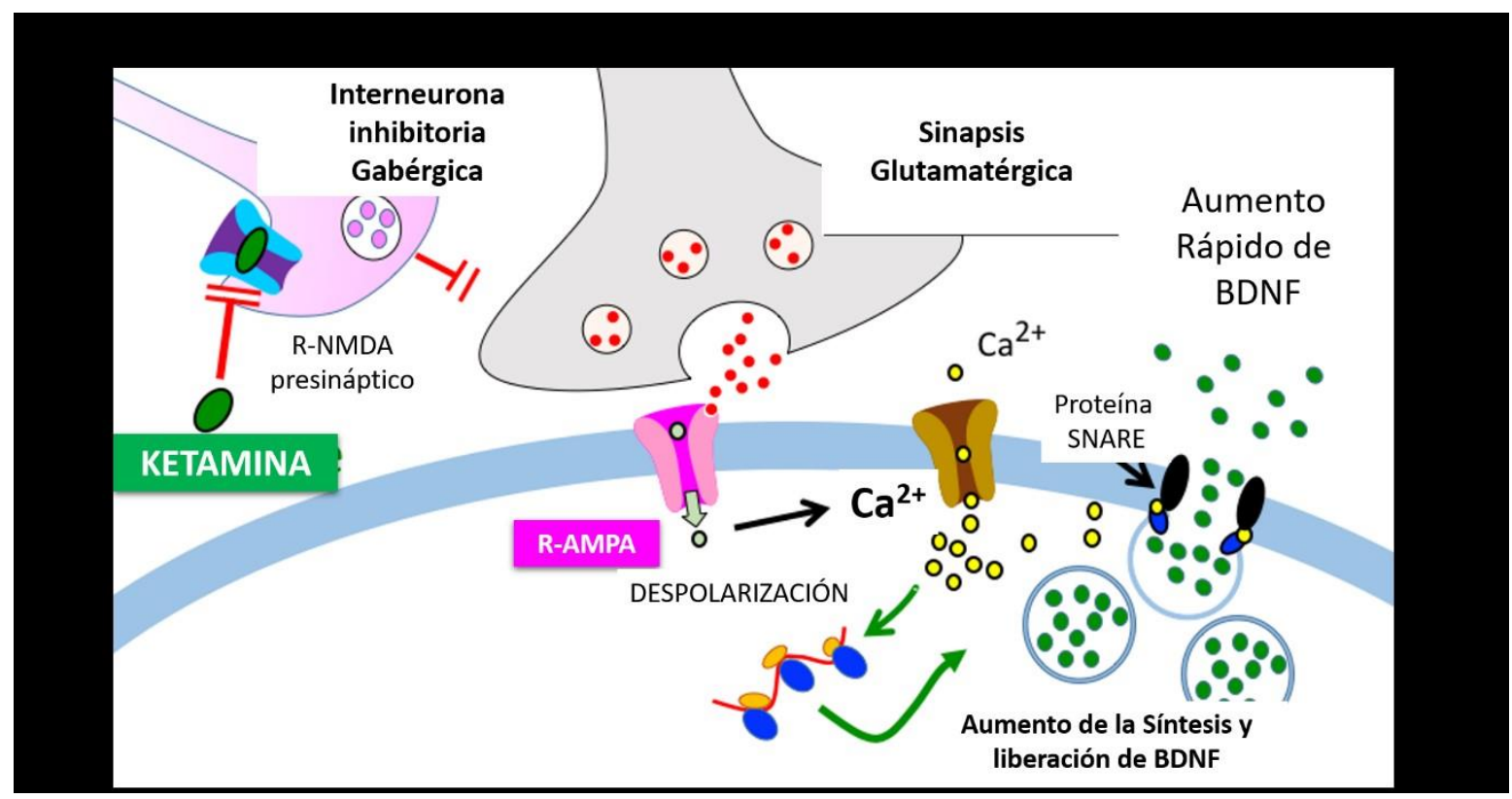

Figura 1 La desinhibición de la interneurona gabérgica por bloqueo de R-NMDA inhibe la liberación de GABA, por lo que se dispara la neurona piramidal glutamatérgica. En consecuencia, se libera glutamato, que estimula los R-AMPA y activa la producción de BDNF.

La vía de señalización BDNF-TrkB parece fundamental para las acciones antidepresivas de la ketamina, ya que, en ratones carentes o con mutaciones (Met rs6265) del gen del BDNF o tratados con anticuerpos anti-BDNF, la ketamina no mostró eficacia antidepresiva [144]. Del mismo modo, ANA12, un inhibidor de TrkB, bloqueó los efectos antidepresivos rápidos y duraderos de ketamina y sus enantiómeros en ratones sometidos a estrés continuado [145]. En conjunto, es probable que la activación prolongada de la cascada BDNF-TrkB en la corteza prefrontal y el hipocampo sea la responsable de los efectos antidepresivos de larga duración de ketamina y sus enantiómeros. Estos datos sugieren que para las acciones antidepresivas de la ketamina es necesario el aumento de la síntesis de BDNF $[140,146]$. Este incremento de BDNF inducido por ketamina puede prevenirse mediante el pretratamiento con NBQX, un antagonista de R-AMPA, lo que indica que este receptor pone en marcha la vía de señalización BDNF-TrkB [135].

Además, se ha podido demostrar que el aumento de BDNF inducido por ketamina es la responsable de la activación de otra vía clave de transducción: la vía de señalización mTOR (mammalian Target of Rapamycin). Esta vía se considera deficitaria en la depresión mayor y su activación estaría implicada en el mecanismo de acción de la ketamina, al regular la plasticidad y el transporte de proteínas sinápticas. La activación de la vía mTOR por ketamina se asocia con un aumento de la transcripción y síntesis de proteínas sinápticas (PSD-95 y sinapsina I), sinaptogénesis, formación de espinas dendríticas, aumento de niveles de BDNF y mejora de la actividad sináptica. Además, aumenta y facilita la síntesis de R-AMPA y su traslado hasta la superficie neuronal. El aumento de los niveles de la proteína Arc del citoesqueleto se observa en la primera hora tras la administración de ketamina y el de las proteínas sinápticas se pone de manifiesto a las 2 horas de la inyección [147]. Además, la activación de mTOR por ketamina se acompaña de la inhibición de la quinasa del factor de elongación eucariota 2 (eEF2), por lo que la liberación del eEF2 produce un 
aumento de la síntesis de proteínas sinápticas, como la BDNF, GluA1-2 y la PSD95 (postsynaptic density protein 95), que promueven la formación y maduración sináptica [148].

La activación mTOR sólo se produce con dosis subanestésicas de ketamina (5 a $10 \mathrm{mg} / \mathrm{kg}$ ), pero no a las dosis altas anestésicas. La rapamicina, un inhibidor selectivo de mTOR, bloquea las acciones de la ketamina, tanto las antidepresivas como las sinaptogénicas. La activación de la vía mTOR por ketamina es específica y no se produce con los antidepresivos tradicionales $[138,148]$.

La activación de la vía de señalización mTOR está relacionada con la GSK-3 (glucógeno sintetasa quinasa-3). En concreto, la desactivación de la GSK-3 induce la activación de mTOR. Los ratones con alteraciones genéticas que afectan a la GSK-3 no manifiestan la respuesta antidepresiva inducida por ketamina. Además, la administración de dosis subumbrales combinadas de ketamina y litio (un inhibidor no selectivo de GSK-3) indujo una activación de la vía de señalización mTORC, con aumento de la sinaptogénesis, y potenció las acciones antidepresivas de ketamina. Estos datos sugieren que la activación de mTORC y la fosforilación de GSK-3 podrían ser un mecanismo involucrado en las acciones antidepresivas de ketamina [140].

Muchos de los efectos sinaptogénicos comentados de la ketamina se relacionan con el receptor AMPA que activa la vía BDNF y la mTOR, pero también el antagonismo de R-NMDA ejercido por ketamina modifica vías de transducción, como hace con la vía de señalización eEF2 (eukaryotic translation elongation factor 2). Se sabe que la estimulación de los R-NMDA por el GLU activa al eEF2, que a su vez inhibe la síntesis de la BDNF. El bloqueo de los R-NMDA por ketamina desactiva a la eEF2 quinasa, por lo que no se activa el eEF2 y se mantiene la producción de BDNF [149].

Por tanto, el aumento de los niveles de BDNF parece ser un elemento muy importante en el efecto antidepresivo de la ketamina. Este incremento depende tanto del efecto directo de la ketamina como antagonista de R-NMDA, como del efecto indirecto sobre R-AMPA por el incremento de GLU liberado. Al menos una parte del efecto antidepresivo de la ketamina, así como el de algunos otros antidepresivos, parece deberse al aumento de BDNF. De hecho, alrededor del 25\% de la población general tiene un polimorfismo (Val66Met) del gen del BDNF, un alelo que bloquea la vía del BDNF, que se asocia con una respuesta marcadamente disminuida al tratamiento con ketamina [138].

Como hemos comentado, la presencia de marcadores inflamatorios en la depresión es frecuente y parece existir una asociación entre ambas entidades patológicas. La ketamina, además de ser eficaz en modelos de depresión provocados por la inflamación [150], normaliza las citoquinas proinflamatorias en ratones, en particular la interleucina 1 beta, el factor de necrosis tumoral (TNFalfa) y la interleucina 6 (IL-6) [151]. Además, estudios en humanos confirman la reducción de las citoquinas proinflamatorias (TNF-alfa) tras la perfusión de ketamina, que se asoció con la reducción de los síntomas depresivos, en pacientes con depresión resistente al tratamiento. Por tanto, la rápida supresión de las citoquinas contribuiría al efecto antidepresivo rápido de la ketamina [152].

Además de las acciones de la ketamina sobre el sistema glutamatérgico, estudios preclínicos indican la posible participación de sistemas monoaminérgicos en las acciones antidepresivas de este agente. En efecto, la ketamina puede modificar el funcionalismo de algunas monoaminas implicadas en la depresión. Así, en un meta-análisis realizado por Kokkinou et al. [153] se pudo observar que la administración aguda de ketamina, en roedores, se asoció con un aumento significativo de los niveles de DA en la corteza, núcleo estriado y núcleo accumbens, en comparación con los controles, junto a un incremento de la actividad de neuronas dopaminérgicas. Además, la administración aguda de ketamina aumentó el número de neuronas dopaminérgicas espontáneamente activas en el área tegmental ventral (VTA), lo que se acompañó de un aumento de los niveles extracelulares de DA en el núcleo accumbens y corteza prefrontal [154]. Estos incrementos de DA en corteza prefrontal y núcleo accumbens podrían estar relacionado con las propiedades antidepresivas y antianhedónicas, pero también con la capacidad adictiva, descritas con la ketamina.

Además, el funcionalismo serotoninérgico también puede estar intervenido por la ketamina. La p-clorofenilalanina, un inhibidor de la síntesis de 5-HT, fue capaz de antagonizar tanto los efectos agudos [155] como sostenidos [156] de la ketamina. Asimismo, la administración en corteza prefrontal del agente farmacológico WAY100635, un antagonista de los receptores 5-HT1A, 
disminuyó los efectos antidepresivos sostenidos de la ketamina [157]. Estos datos hablan a favor de una participación serotoninérgica en el mecanismo de acción de la ketamina.

Por otra parte, el hecho de que la ketamina sea un anestésico y que además se emplee como sustancia de abuso, abrió la posibilidad de que el funcionalismo opioide participara en su actividad antidepresiva. Aunque es conocido que los R-NMDA y opioides Mu comparten localización en determinadas áreas cerebrales, existiendo relaciones moduladoras entre ambos, la ketamina, a dosis terapéuticas, no parece poseer afinidad por ninguno de los receptores opioides [158]. Dos estudios recientes, con una amplia difusión, mostraron que el pretratamiento con $50 \mathrm{mg}$ de naltrexona abolía el efecto antidepresivo y antisuicida de ketamina en infusión [159-160]. Sin embargo, en estos estudios la muestra de pacientes y la falta de un grupo control devalúa las conclusiones. Además, en otro estudio realizado en pacientes con depresión mayor y trastornos por consumo de alcohol, el pretratamiento con naltrexona no evitó los efectos antidepresivos de la ketamina [161]. Además, el uso conjunto de buprenorfina, metadona o naltrexona tampoco inhibió el efecto antidepresivo de la ketamina [162]. Todavía queda mucho por aclarar sobre la afectación, si la hay, del sistema opioide en el efecto antidepresivo de la ketamina [163-164].

El espectro de acciones farmacológicas de ketamina es tan amplio que se traduce por un amplio abanico clínico, donde destacan sus propiedades como anestésico disociativo y, negativamente, su potencial adictivo. No obstante, en las dos últimas décadas, el interés por la ketamina se ha desplazado al tratamiento antidepresivo, que es el motivo que nos ocupa. La capacidad antidepresiva experimental de la ketamina se demostró en 1975, en varios modelos animales de depresión [165]. Sin embargo, sus propiedades psicotomiméticas en los roedores ensombrecieron su actividad antidepresiva [150].

El descubrimiento de los efectos antidepresivos de la ketamina en humanos comenzó en la década de 1970, por algunos individuos que usaban esta droga, también la fenciclidina, para mejorar los síntomas depresivos cuando los antidepresivos habituales no eran eficaces. Sin embargo, por tratarse de sustancias ilícitas, "drogas", no se realizaron estudios clínicos sobre su potencial como antidepresivo [166-167]. Hasta el año 2000 no se realizó el primer estudio clínico con ketamina en depresión. Berman et al. [168], en un estudio aleatorizado a doble ciego, administraron ketamina en infusión intravenosa vs. solución salina a 7 sujetos con depresión mayor. Después de la perfusión de ketamina, los sujetos presentaron una mejora significativa en los síntomas depresivos, dentro de las 72 horas, hecho no observado con el placebo. Sin embargo, este trabajo no tuvo un impacto inmediato, por no atreverse otros investigadores a probar una "droga" con potencial de abuso y efectos psicotomiméticos. Pese a ello, el hallazgo fue replicado por Zarate Jr. et al. [169] en pacientes con depresión resistentes al tratamiento y desde entonces muchos estudios han confirmado los efectos antidepresivos de ketamina para pacientes resistentes al tratamiento con depresión mayor, trastorno bipolar e ideación suicida [50,170].

En efecto, numerosos estudios controlados con placebo han demostrado que la ketamina, a dosis subanestésicas, tiene efectos antidepresivos rápidos, robustos y relativamente sostenidos en individuos con trastorno depresivo mayor resistente al tratamiento y en depresión bipolar. Basándose en esta importante evidencia, los investigadores han estudiado si otros antagonistas del R-NMDA tendrían efectos antidepresivos similares a los de la ketamina. Desafortunadamente, otros antagonistas o moduladores del R-NMDA (por ejemplo, GLYX-13, CERC- 301) han fallado en la clínica. Estas observaciones podrían indicar que la ketamina no es solo un antagonista R-NMDA, sino que tiene otras propiedades que marcan la diferencia. Precisamente esta amplitud farmacodinámica de la ketamina, la ha hecho una herramienta farmacológica, tanto preclínica como clínica, para identificar características prometedoras de futuros antidepresivos [170].

Las propiedades únicas, rapidez de acción, eficacia en depresión resistente y actividad antisuicida, de ketamina han hecho que proliferen "las clínicas de ketamina", en ocasiones sustituyendo a las clínicas de "electroshock". Se ha sugerido que la administración de ketamina (0,5 $\mathrm{mg} / \mathrm{kg}$ ), dos o tres veces por semana, es suficiente para mantener la eficacia antidepresiva durante 15 días, en pacientes con depresión resistente al tratamiento. Una limitación importante del tratamiento tras la perfusión única de ketamina es que los pacientes a menudo recaen en un plazo de 1 a 2 
semanas. Sin embargo, la administración repetida de ketamina (por ejemplo, dos veces por semana) parece mantener los efectos antidepresivos [87-171]. Es destacable la propiedad antisuicida de inicio rápido de la ketamina, que se postula que pueda deberse a la mejora de la neuroplasticidad [172]. El efecto antisuicida se produce incluso en pacientes que no responden al efecto antidepresivo de la ketamina. Aproximadamente a los 40 minutos de la administración de ketamina $(0,5 \mathrm{mg} / \mathrm{kg}) \mathrm{se}$ produce una mejoría de la ideación suicida que puede durar hasta 10 días [173]. Además, la ketamina ha demostrado un efecto antianhedónico independiente de la eficacia sobre los síntomas depresivos, efecto que puede durar hasta 14 días. Hipotéticamente, la reducción de la anhedonia podría ser el mecanismo por el cual la ketamina reduce los pensamientos suicidas [174]. No obstante, en la actualidad, existe una carencia de datos sobre la seguridad y eficacia a largo plazo de ketamina, lo cual es muy importante, dado el potencial de efectos secundarios graves de este agente [150].

Un hecho trascendental ha sido la aprobación por la FDA, en marzo de 2019, del enantiómero S de la ketamina: la esketamina, que también ha sido aprobada por la Agencia Europea del Medicamento. En la actualidad, el desarrollo clínico de esketamina supera con creces, tanto en metodología científica, farmacovigilancia, así como en número de pacientes reclutados, al de la ketamina, por lo que le dedicamos el siguiente apartado [175].

\section{Esketamina (Spravato ${ }^{\circledR}$ ): primer antidepresivo de acción rápida aprobado para el tratamiento de la depresión resistente. Confirmación de la hipótesis glutamatérgica de la depresión}

El 5 de marzo de 2019, la esketamina intranasal fue aprobada por la FDA, y el 18 de diciembre de 2019 por la Agencia Europea del Medicamento (EMA), para el "tratamiento de la depresión resistente al tratamiento en adultos. En concreto, ketamina (Spravato $\left.{ }^{\circledR}\right)$, en combinación con un ISRS o SNRI, está indicado para adultos con trastorno depresivo mayor resistente al tratamiento, que no han respondido al menos a dos tratamientos diferentes con antidepresivos en un cuadro actual depresivo moderado a grave" [175].

La esketamina, es el S-enantiómero de la R-S-ketamina. El R-enantiómero presenta también actividad antidepresiva experimental, pero no es una realidad clínica, ya que aún están en curso ensayos clínicos en humanos. La esketamina tiene una afinidad por los R-NMDA 1,5 veces mayor que la ketamina racémica y de tres a cuatro veces mayor que la del R-enantiómero [150]. La alta afinidad de esketamina por R-NMDA permite el uso de dosis bajas, por lo que ocupa un menor volumen de administración, lo que facilita su administración intranasal. Por esta vía de administración, el fármaco accede de forma directa al SNC, sin sufrir metabolismo intestinal o hepático, lo que facilita su rápido inicio de acción [176].

El desarrollo clínico de esketamina se inició con un ensayo doble ciego, multicéntrico, aleatorizado, controlado con placebo, en el que se observó que su administración, por perfusión intravenosa $(0,2$ y $0,40 \mathrm{mg} / \mathrm{kg})$ mostró un efecto antidepresivo rápido y robusto en pacientes con depresión resistente al tratamiento. Los eventos adversos más comunes fueron dolor de cabeza, náuseas y disociación [177]. Este estudio pionero de Singh et al. [177], dio paso a un programa de desarrollo clínico por Janssen Pharmaceutica, en estrecha colaboración con las autoridades sanitarias (FDA y EMA), con todas las directrices sanitarias para establecer la eficacia y seguridad de esketamina en pacientes con depresión resistente al tratamiento. A destacar que estos pacientes son generalmente excluidos de los ensayos clínicos de antidepresivos. Este programa incluyó 19 estudios de fase I, cuatro estudios de fase II y seis estudios de fase III en pacientes con depresión resistente. Se incluyó un estudio de seguridad a largo plazo, con un seguimiento de hasta un año [178], así como un estudio de mantenimiento, en el que se evaluó la prevención de las recaídas [179]. El fármaco fue aprobado en base a dos estudios positivos de fase III [179-180], y con los datos de apoyo de otros estudios adicionales de fase II y III que demostraban la eficacia constante de la esketamina y aportaban pruebas sobre su seguridad a largo plazo [181].

Comentar cada uno de estos estudios sería demasiado prolijo, por lo que recurrir a los datos de una reciente revisión sistemática y meta-análisis realizado con esketamina intranasal por Zheng et al. [182] nos parece más ilustrativo. En este estudio, utilizando la MADRS (Montgomery Asberg Depression Rating Scale), se pudo comprobar una superioridad significativa $(\mathrm{p}<0,001)$ de 
esketamina nasal sobre el placebo en la respuesta al tratamiento antidepresivo, así como en la remisión ( $\mathrm{p}=0,0004)$, en la evaluación realizada al final del tratamiento. Es importante destacar que, en comparación con el placebo, la respuesta comenzó en menos de 2 horas tras la administración intranasal, alcanzando un máximo a las 24 horas y con una duración de al menos 28 días. Aunque la tasa de abandonos por falta de tolerabilidad fue superior con la esketamina, la tasa de abandonos totales por efectos adversos e ineficacia fue igual en los dos grupos. Los autores de este meta-análisis señalan que la esketamina intranasal mostró un efecto antidepresivo ultrarrápido, siendo relativamente segura y con buena tolerabilidad por los pacientes con depresión mayor resistentes al tratamiento [182].

No obstante, para evaluar los efectos terapéuticos, la seguridad y tolerabilidad a largo plazo, serían necesarios más estudios controlados. Un estudio controlado a largo plazo (16 semanas), la esketamina mostró una superioridad clínicamente significativa en la prevención de recaídas en comparación con el placebo. En este estudio, la esketamina, al placebo, redujo en un 51\% la recaída en los pacientes que se encontraban en remisión estable y en un $70 \%$ en los pacientes con respuesta estable al inicio del tratamiento [179].

En otro estudio multicéntrico a largo plazo ( 1 año), abierto, de fase III, realizado en 802 pacientes mayores de 18 años, se evaluó la esketamina. Como en todos los estudios, los pacientes recibían tratamiento con un antidepresivo convencional y esketamina intranasal a las dosis de $28 \mathrm{mg}, 56 \mathrm{mg}$ ó $84 \mathrm{mg}$, administrada dos veces por semana durante las 4 primeras semanas de tratamiento (fase de inducción). Posteriormente, los pacientes que respondieron al tratamiento recibieron una dosis de esketamina semanal o quincenal durante 48 semanas (fase de mantenimiento). El $75 \%$ de los pacientes completaron la fase de inducción y el $25 \%$ la fase de mantenimiento. Los efectos adversos emergentes fueron mareos $(32,9 \%)$, cuadro disociativo $(27,6 \%)$, náuseas $(25,1 \%)$ y dolor de cabeza $(24,9 \%)$. Los síntomas disociativos del tratamiento emergente fueron transitorios y generalmente se resolvieron dentro de la primera hora y media tras la administración. Los autores señalan que la esketamina intranasal a largo plazo, asociada a terapia con antidepresivos orales, tiene un perfil de seguridad manejable y su eficacia antidepresiva pemanece en la fase de mantenimiento de hasta un año [178].

Además, se ha realizado dos estudios en fase III, doble ciego, multicéntricos, en 456 adultos con un trastorno depresivo mayor, con ideación suicida e intento de suicidio activo, que requerían hospitalización psiquiátrica. Estos estudios se denominaron "ASPIRE I" [183] y "ASPIRE II" [184] y se realizaron en un grupo de pacientes que, por su gravedad, son excluidos habitualmente en los ensayos con antidepresivos convencionales. En estos estudios, la administración de esketamina, a la dosis de $84 \mathrm{mg}$ dos veces por semana, durante 4 semanas, asociada a terapia coadyuvante con antidepresivos orales y cuidados hospitalarios habituales para estos pacientes, se asoció a una mejoría de la sintomatología depresiva en la escala de MADRS, respecto a los pacientes tratados con placebo y antidepresivos orales e idénticos cuidados sanitarios. Las diferencias en eficacia antidepresiva se manifiestan desde las 4 horas de iniciado el tratamiento y el efecto se mantiene durante las cuatro semanas de tratamiento. Pese a que la mejoría en la ideación suicida no se diferenció estadísticamente entre ambos grupos de pacientes, la eficacia antidepresiva de esketamina en pacientes con niveles altos de suicidialidad fue significativamente superior a la del grupo control [184], por lo que el promotor ha solicitado de la EMA la indicación de esketamina para este tipo de pacientes.

Por otra parte, se ha estudiado en 1.708 pacientes, procedentes de seis ensayos clínicos controlados, la seguridad cardiovascular de esketamina. La esketamina nasal se asoció con elevaciones de la presión arterial, que fueron generalmente transitorias, asintomáticas, y que desaparecieron sin necesidad de medicación de rescate. En el programa de desarrollo de esketamina no se observó ningún efecto adverso, clínicamente relevante, sobre los parámetros del ECG. La seguridad cardiovascular de esketamina, asociada a antidepresivos, cuando se administró a pacientes sin hipertensión o con hipertensión controlada, debe realizarse bajo observación clínica, de acuerdo con las instrucciones de la ficha técnica de Spravato ${ }^{\circledR}$. Los pacientes con afecciones cardiovasculares y cerebrovasculares no deben ser tratados con esketamina si el riesgo supera el beneficio [185].

Con ketamina se han reportado casos de abuso, por lo que se recomienda que la terapia prolongada con esketamina sea cuidadosamente monitorizada. La dosis habitualmente consumida 
en usuarios frecuentes de ketamina puede llegar a ser de unos tres gramos diarios. Puesto que la esketamina intranasal se administra con un dispositivo desechable que contiene $28 \mathrm{mg}$, es decir una cantidad 100 veces inferior a la de abuso habitual, y bajo la observación de un profesional sanitario, la probabilidad de abuso parece estar minimizada. De hecho, durante los ensayos clínicos no se reportaron casos de abuso con esketamina [186].

Por los datos aportados, se puede afirmar que la hipótesis glutamatérgica de la depresión no se queda en un aspecto teórico, sino que entra de pleno en el difícil campo del tratamiento de la depresión resistente, gracias a la aprobación de la esketamina. El tratamiento recomendado con esketamina consiste en la administración por inhalación nasal dos veces por semana, durante 4 semanas, con dosis de refuerzo (técnicamente: "dosis de rescate") si no se consigue un control adecuado. El tratamiento con esketamina se debe asociar a un tratamiento de base con alguno de los antidepresivos, ISRS o IRSN, por vía oral. La esketamina debe administrarse en un entorno hospitalario, supervisando al paciente durante las primeras dos horas tras la administración.

La esketamina intranasal es una alternativa terapéutica para pacientes con depresión resistente al tratamiento. Tras casi 30 años de investigación centrados en el R-NMDA del GLU, la reciente aprobación de la esketamina intranasal para el tratamiento de la depresión mayor, en pacientes que no han respondido al menos a 2 antidepresivos, supone una opción terapéutica única, hasta la fecha, para el tratamiento de estos pacientes. La esketamina intranasal ofrece una rápida reducción de los síntomas depresivos, que se mantiene en el tiempo, disminuyendo el riesgo de recaída y con un perfil favorable de tolerabilidad [186-187].

\section{Conclusiones}

Durante más de 60 años, los fármacos empleados en el tratamiento de la depresión, aún vigentes, iniciaban sus efectos antidepresivos incrementando las tasas sinápticas de 5-HT y/o NA. Este mecanismo fue tan influyente que permitió acuñar la "hipótesis monoaminérgica de la depresión".

El hecho de que los antidepresivos tengan este mecanismo de acción monoaminérgico común, condiciona su limitada eficacia, su inicio retardado de acción, así como sus efectos adversos y seguridad clínica.

La búsqueda de antidepresivos con un perfil clínico diferente a los antidepresivos convencionales pasa por explorar la patogenia de la depresión y utilizar los hallazgos fisiopatológicos como posibles dianas terapéuticas.

La depresión es una patología compleja, en cuya fisiopatología parecen intervenir mecanismos endocrinológicos, sistemas funcionales de neuropéptidos, el componente inflamatorio y diversos mecanismos de neurotransmisión.

La mayoría de estos mecanismos fisiopatológicos han sido utilizados como dianas para encontrar nuevos y diferentes antidepresivos. Sin embargo, salvo excepciones, los resultados clínicos han sido esquivos.

Desde el punto de vista clínico, la exploración de mecanismos gabérgicos ha dado lugar al descubrimiento de la alopregnanolona, un modulador alostérico positivo de los R-GABA-A, que ha sido aprobada con la indicación de la depresión postparto.

Además, la exploración de los complejos mecanismo glutamatérgicos ha servido de ayuda para esclarecer que el enantiómero $S$ de la ketamina, denominado esketamina, es eficaz en la depresión resistente al tratamiento y presenta un inicio de acción rápido.

La hipótesis glutamatérgica de la depresión, explorada durante tres décadas, ha permitido ampliar el arsenal terapéutico antidepresivo que hasta ahora solo disparaba con mecanismos monoaminérgicos.

Contribución de los autores: Los tres autores han contribuido por igual a la redacción y discusión de este trabajo.

Conflictos de Intereses: En el presente trabajo "los autores no declaran conflicto de intereses". 


\section{Abreviaturas}

Las siguientes abreviaturas son usadas en este manuscrito:

5-HT: serotonina

ACC: corteza cingulada anterior

ADT: antidepresivos tricíclicos

AINE: antinflamatorios no esteroídicos

AMPA: amino-3-hidroxi-5-metil-4-isoxazolpropano

AVP: arginina-vasopresina

BDNF: brain derived neurotrophic factor

BHE: barrera hematoencefálica

CPF: corteza prefrontal

CRH: hormona liberadora de corticotropina

DA: dopamina

EAAT: transportador de aminoácidos excitatorios

eEF2: eukaryotic translation elongation factor 2

ELA: esclerosis lateral amiotrófica

EMA: Agencia Europea del Medicamento

FDA: Food and Drug Administration

FSL: modelo de ratas deprimidas

GABA: ácido gamma amino-butírico

GAL: galanina

GLU: glutamato

GLUT1v: transportador de GLU vesicular 1

Glx: la suma de niveles de GLU y glutamina

GSK-3: glucógeno sintetasa quinasa-3

HHA: eje hipotálamo-hipófiso-adrenal

IMAO: inhibidores de la monoaminooxidasa

IRNA: inhibidores selectivos de la recaptación de noradrenalina

IRNS: inhibidores de la recaptación de noradrenalina y serotonina

ISRS: inhibidores selectivos de la recaptación de serotonina

LC: locus coeruleus

LCR: líquido cefalorraquídeo

MADRS: Montgomery Asberg Depression Rating Scale

mTOR: mammalian target of rapamycin

NA: noradrenalina

NK: neuroquinina

NMDA: N-metil-D-aspartato

NML: National Library of Medicine

NPY: neuropéptido $Y$

OXT: oxitocina

SNAP-25: synaptosomal-associated protein 25

SNARE: soluble N-ethylmaleimide sensitive factor attachment protein receptor

SNC: sistema nervioso central

SNP: polimorfismos de nucleótidos únicos

SP: sustancia P

TNF: tumor necrosis factor

TRH: tyrotrophin releasing hormone

TrkB: tropomiosina relacionada con la cinasa B

VAMP: vesicle-associated membrane protein

VTA: área tegmental ventral 


\section{Referencias bibliográficas}

1. López-Muñoz F, Alamo C, Juckel G, Assion HJ. Half a century of antidepressant drugs. On the clinical introduction of monoamine oxidase inhibitors, tricyclics and tetracyclics. Part I: Monoamine oxidase inhibitors. J Clin Psychopharmacol. 2007; 27: 555-9

2. Fangmann P, Assion HJ, Juckel G, Álamo C, López-Muñoz F. Half a century of antidepressant drugs. On the clinical introduction of monoamine oxidase inhibitors, tricyclics and tetracyclics. Part II: Tricyclics and tetracyclics. J Clin Psychopharmacol. 2008; 28: 1-4

3. Álamo C, López-Muñoz F, García-García P, Rubio G. Modulación noradrenérgica en la fisiopatología y terapéutica de la depresión: una visión actual. Madrid: McGraw-Hill Interamericana de España, S.A.U., 2007

4. López-Muñoz F, Alamo C. Monoaminergic neurotransmission: the history of the discovery of antidepressants from 1950s until today. Curr Pharm Des. 2009; 15: 1563-86.

5. López-Muñoz F, Álamo C. Neurobiology of Depression. Boca Raton: CRC Press Taylor \& Francis Group, 2012.

6. López-Muñoz F, Álamo C. Neurobiology of monoaminergic neurotransmission and antidepressants. En: Srinivasan V, Brzezinski A, Oter S, Shillcutt SD, eds. Melatonin and Melatonergic Drugs in Clinical Practice. New Delhi: Springer International, 2014, pp. 321-341

7. Sanacora G, Treccani G, Popoli M. Towards a glutamate hypothesis of depression: an emerging frontier of neuropsychopharmacology for mood disorders. Neuropharmacology. 2012; 62: 63-77.

8. López-Muñoz F, Álamo C, Rubio G, García-García P, Martín-Agueda B, Cuenca E. Bibliometric analysis of biomedical publications on SSRIs during the period 1980-2000. Depression Anxiety. 2003; 18: 95-103.

9. Álamo C, López-Muñoz F. Optimizando el tratamiento de los pacientes deprimidos. Depresión y ritmos circadianos: relación farmacológica. El papel de la agomelatina. Rev Psiquiatr Salud Ment (Barc). 2010; 3: S3-11

10. Álamo C, García-Garcia P, Lopez-Muñoz F, Zaragozá C. Tianeptine, an atypical pharmacological approach to depression. Rev Psiquiatr Salud Ment (Barc). 2019; 12: 170-86.

11. Seguí J, López-Muñoz F, Alamo C, Camarasa X, García-García P, Pardo A. Effects of adjunctive reboxetine in patients with duloxetine-resistant depression: a 12-week prospective study. J Psychopharmacol. 2010; 24: 1201-7.

12. Li YF. A hypothesis of monoamine (5-HT) - Glutamate/GABA long neural circuit: Aiming for fast-onset antidepressant discovery. Pharmacol Ther. 2020; 208: 107494.

13. López-Muñoz F, Álamo C. Historical evolution of the neurotransmission concept. J Neural Transm. 2009; 116: 515-33.

14. Altemus M. Hormone-specific psychiatric disorders: do they exist? Arch Women Ment Health. 2010; 13: 25-6.

15. Chávez-Castillo M, Núñez V, Nava M, Ortega Á, Rojas M, Bermúdez V, Rojas-Quintero J. Depression as a Neuroendocrine Disorder: Emerging Neuropsychopharmacological Approaches beyond Monoamines. Adv Pharmacol Sci. 2019; 7943481.

16. Cuenca E, Álamo C, Gibert J, Serrano MI, Galiana J. Algunos aspectos farmacológicos, bioquímicos y clínicos de los péptidos hipotalámicos TRH y MIF. Madrid: II Congreso de la Federación Española de Sociedades de Biología Experimental, 1981.

17. Demartini B, Ranieri R, Masu A, Selle V, Scarone S, Gambini O. Depressive symptoms and major depressive disorder in patients affected by subclinical hypothyroidism. J Nerv Ment Dis. 2014; 202: 603-7.

18. Sanghvi R, Mogalian E, Machatha SG, Narazaki R, Karlage KL, Jain P, et al. Preformulation and pharmacokinetic studies on antalarmin: a novel stress inhibitor. J Pharm Sci. 2009; 98: 205-14.

19. Menke A. Is the HPA Axis as Target for Depression Outdated, or Is There a New Hope? Front Psychiatry. 2019; 10: 101.

20. Whedon JM, KizhakkeVeettil A, Rugo NA, Kieffer KA. Bioidentical estrogen for menopausal depressive symptoms: a systematic review and meta-analysis. J Women Health 2017; 26: 18-28.

21. Jung SJ, Shin A, Kang D. Hormone-related factors and post-menopausal onset depression: results from KNHANES (2010-2012). J Affect Disord. 2015; 175: 176-83.

22. McHenry J, Carrier N, Hull E, Kabbaj M. Sex differences in anxiety and depression: role of testosterone. Front Neuroendocrinol. 2014; 35: 42-57. 
23. Gołyszny M, Obuchowicz E. Are neuropeptides relevant for the mechanism of action of SSRIs? Neuropeptides. 2019; 75: 1-17.

24. Griebel G, Beeské S, Stahl SM. The vasopressin V(1b) receptor antagonist SSR149415 in the treatment of major depressive and generalized anxiety disorders: results from 4 randomized, double-blind, placebocontrolled studies. J Clin Psychiatry. 2012; 73:1403-411.

25. Meynen G, Unmehopa UA, Hofman MA, Swaab DF, Hoogendijk WJG. Hypothalamic oxytocin mRNA expression and melancholic depression. Mol Psychiatr. 2007; 12: 118-9.

26. Catena-Dell'Osso M, Fagiolini A, Marazziti D, Baroni S, Bellantuono C. Non-monoaminergic targets for the development of antidepressants: focus on neuropeptides. Mini Rev Med Chem. 2013; 13: 2-10.

27. Kramer MS, Cutler N, Feighner J, Shrivastava R, Carman J, Sramek JJ, et al. Distinct mechanism for antidepressant activity by blockade of central substance P receptors. Science. 1998; 281 (5383): 1640-5.

28. Nyman M, Eskola O, Kajander J, Jokinen R, Penttinen J, Karjalainen T, et al. Brain neurokinin-1 receptor availability in never-medicated patients with major depression - A pilot study. J Affect Disord. 2019; 242: 188-94.

29. Rupniak NMJ, Kramer MS. NK1 receptor antagonists for depression: Why a validated concept was abandoned. J Affect Disord. 2017; 223: 121-5.

30. Tural U, Iosifescu DV. Neuropeptide Y in PTSD, MDD, and chronic stress: A systematic review and metaanalysis. J Neurosci Res. 2020; 98: 950-63.

31. Morales-Medina JC, Dumont Y, Benoit CE, Bastianetto S, Flores G, Fournier A, Quirion R. Role of neuropeptide $\mathrm{Y} \mathrm{Y}_{1}$ and $\mathrm{Y}_{2}$ receptors on behavioral despair in a rat model of depression with co-morbid anxiety. Neuropharmacology. 2012; 62: 200-8.

32. Enman NM, Sabban EL, McGonigle P, Van Bockstaele EJ. Targeting the Neuropeptide Y System in Stressrelated Psychiatric Disorders. Neurobiol Stress. 2015; 1: 33-43.

33. Juhasz G, Hullam G, Eszlari N, Gonda X, Antal P, Anderson IM, et al. Brain galanin system genes interact with life stresses in depression-related phenotypes. Proc Natl Acad Sci USA. 2014; 111(16): E1666-73.

34. Demsie DG, Altaye BM, Weldekidan E, Gebremedhin H, Alema NM, Tefera MM, et al. Galanin Receptors as Drug Target for Novel Antidepressants: Review. Biologics Targets Ther. 2020: 14; 37-45.

35. Block SG, Nemeroff CB. Emerging antidepressants to treat major depressive disorder. Asian J Psychiatr. 2014; 12: 7-16

36. Mahli GS, Mann JJ. Depression. Lancet. 2018; 392: 2299-312.

37. Andrade C. Antidepressant augmentation with anti-inflammatory agents. J Clin Psychiatry. 2014; 75: 9757.

38. Vojvodic J, Mihajlovic G, Vojvodic P, Radomirovic D, Vojvodic A, Vlaskovic-Jovicevic T, et al. The Impact of Immunological Factors on Depression Treatment - Relation Between Antidepressants and Immunomodulation Agents. Open Acc Maced J Med Sci. 2019; 7: 3064-9.

39. Ragguett RM, Tamura JK, McIntyre RS. Keeping up with the clinical advances: depression. CNS Spectr. 2019; 24: 28-36.

40. Berrocoso E, Sanchez-Blazquez P, Garzon J, Mico JA. Opiates as antidepressants. Curr Pharm Design. 2009; 15: $1612-22$

41. Le Merrer J, Becker JAJ, Befort K, Kieffer BL. Reward processing by the opioid system in the brain. Physiol Rev. 2009; 89: 1379-412.

42. Zajecka JM, Stanford AD, Memisoglu A, Martin WF, Pathak S. Buprenorphine/samidorphan combination for the adjunctive treatment of major depressive disorder: results of a phase III clinical trial (FORWARD3). Neuropsychiatr Dis Treat. 2019; 15: 795-808.

43. Browne C, Lucki I. Targeting opioid dysregulation in depression for the development of novel therapeutics. Pharmacol Ther. 2019; 201: 51-76.

44. Bhagwagar Z, Wylezinska M, Taylor M, Jezzard P, Matthews PM, Cowen PJ. Increased brain GABA concentrations following acute administration of a selective serotonin reuptake inhibitor. Am J Psychiatry. 2004; 161: 368-70.

45. Bhagwagar Z, Wylezinska M, Jezzard P, Evans J, Boorman E, M Matthews P, J Cowen P. Low GABA concentrations in occipital cortex and anterior cingulate cortex in medication-free, recovered depressed patients. Int J Neuropsychopharmacol. 2008; 11: 255-60.

46. Benasi G, Guidi J, Offidani E, Balon R, Rickels K, Fava G, A: Benzodiazepines as a Monotherapy in Depressive Disorders: A Systematic Review. Psychother Psychosom. 2018; 87: 65-74. 
47. Álamo C, Cuenca E, López-Muñoz F. Avances en psicofarmacología y perspectivas de futuro. En: Avendaño MC, Tamargo J, eds. Nuevos avances en medicamentos. Madrid: Real Academia Nacional de Farmacia, 2004, pp. 351-429

48. Dale E, Bang-Andersen B, Sánchez C. Emerging mechanisms and treatments for depression beyond SSRIs and SNRIs. Biochem Pharmacol. 2015; 95: 81-97.

49. Trullas R, Skolnick P. Functional antagonists at the NMDA receptor complex exhibit antidepressant actions. Eur J Pharmacol. 1990; 185: 1-10.

50. Álamo C, López-Muñoz F, García-García P. It is possible find an antidepressant with faster onset of action? Ketamine: Promise or reality? Ann Depress Anxiety. 2014; 1 (5): 4. id1021.

51. Takamori S. VGLUTs: 'exciting' times 151. for glutamatergic research? Neurosci Res. 2006; 55: 343-51.

52. Hashimoto K, Bruno D, Nierenberg J, Marmar CR, Zetterberg H, Blennow K, Pomara N. Abnormality in glutamine-glutamate cycle in the cerebrospinal fluid of cognitively intact elderly individuals with major depressive disorder: a 3-year follow-up study. Transl Psychiatry. 2016; 6: e744.

53. Magi S, Piccirillo, S, Amoroso S. The dual face of glutamate: from a neurotoxin to a potential survival factor-metabolic implications in health and disease. Cell Mol Life Sci. 2019; 76: 1473-88.

54. Kew JC, Kemp J. Ionotropic and metabotropic glutamate receptor structure and pharmacology. Psychopharmacology (Berl). 2005; 179: 4-29.

55. Hillhouse TM, Porter JH. A brief history of the development of antidepressant drugs: from monoamines to glutamate. Exp Clin Psychopharmacol. 2015; 23: 1-21.

56. Cao YJ, Wang Q, Zheng XX, Cheng Y, Zhang Y. Involvement of SNARE complex in the hippocampus and prefrontal cortex of offspring with depression induced by prenatal stress. J Affect Disord. 2018; 235: 374 83.

57. Garcia-Garcia AL, Elizalde N, Matrov D, Harro J, Wojcik SM, Venzala E, et al. Increased vulnerability to depressive-like behavior of mice with decreased expression of VGLUT1. Biol Psychiatry. 2009; 66: 275-82.

58. García-García AL, Venzala E, Elizalde N, Ramírez MJ, Urbiola A, Del Rio J, et al. Regulation of serotonin (5-HT) function by a VGLUT1 dependent glutamate pathway. Neuropharmacology. 2013; 70: 190-9.

59. Zink M, Vollmayr B, Gebicke-Haerter PJ, Henn FA. Reduced expression of glutamate transporters vGluT1, EAAT2 and EAAT4 in learned helpless rats, an animal model of depression. Neuropharmacology. 2010; 58: 465-73.

60. Uezato A, Meador-Woodruff JH, McCullumsmith RE. Vesicular glutamate transporter mRNA expression in the medial temporal lobe in major depressive disorder, bipolar disorder, and schizophrenia. Bipolar Disord. 2009; 11: 711-25.

61. Elizalde N, Pastor PM, Garcia-García AL, Serres F, Venzala E, Huarte J, et al. Regulation of markers of synaptic function in mouse models of depression: chronic mild stress and decreased expression of VGLUT1. J Neurochem. 2010; 114: 1302-14.

62. Zhao J, Verwer RWH, Gao SF, Qi XR, Lucassen PJ, Kessels HW, Swaab DF. Prefrontal alterations in GABAergic and glutamatergic gene expression in relation to depression and suicide. J Psychiatr Res. 2018; 102: 261-74.

63. Yoon TY, Munson M. SNARE complex assembly and disassembly. Curr Biol. 2018; 28 (8): R397-R401.

64. Najera K, Fagan BM, Thompson PM. SNAP-25 in Major Psychiatric Disorders: A Review. Neuroscience. 2019; 420: 79-85.

65. Wang Q, Wang Y, Ji W, Zhou G, He K, Li Z, et al. SNAP25 is associated with schizophrenia and major depressive disorder in the Han Chinese population. J Clin Psychiatr. 2015; 76: e76-e82.

66. Honer WG, Falkai P, Bayer TA, Xie J, Hu L, Li H, et al. Abnormalities of SNARE mechanism proteins in anterior frontal cortex in severe mental illness. Cereb Cortex 2002; 12: 349-56.

67. Bonanno G, Giambelli R, Raiteri L, Tiraboschi E, Zappettini S, Musazzi L, et al. Chronic antidepressants reduce depolarization evoked glutamate release and protein interactions favoring formation of SNARE complex in hippocampus. J. Neurosci. 2005; 25: 3270-9.

68. Lazarevic V, Mantas I, Flais I, Svenningsson P. Fluoxetine Suppresses Glutamate- and GABA-Mediated Neurotransmission by Altering SNARE Complex. Int J Mol Sci. 2019; 20 (17): 4247.

69. O'Donovan SM, Sullivan CR, McCullumsmith RE. The role of glutamate transporters in the pathophysiology of neuropsychiatric disorders. NPJ Schizophr. 2017; 3 (1): 32.

70. Medina A, Burke S, Thompson RC, Bunney W Jr, Myers RM, Schatzberg A, et al. Glutamate transporters: a key piece in the glutamate puzzle of major depressive disorder. J Psychiatr Res. 2013; 47: 1150-6. 
71. Zhang XH, Jia N, Zhao XY, Tang GK, Guan LX, Wang D, et al. Involvement of pGluR1, EAAT2 and EAAT3 in offspring depression induced by prenatal stress. Neuroscience. 2013; 250: 333-41.

72. Chen JX, Yao LH, Xu BB, Qian K, Wang HL, Liu ZC, et al. Glutamate transporter 1-mediated antidepressant-like effect in a rat model of chronic unpredictable stress. J Huazhong Univ Sci Technolog Med Sci. 2014; 34: 838-44.

73. Reagan LP, Rosell DR, Wood GE, Spedding M, Muñoz C, Rothstein J, et al. Chronic restraint stress upregulates GLT-1 mRNA and protein expression in the rat hippocampus: Reversal by tianeptine. Proc Natl Acad Sci USA. 2004; 101: 2179-84.

74. Frizzo ME. The Effect of Glutamatergic Modulators on Extracellular Glutamate: How Does this Information Contribute to the Discovery of Novel Antidepressants?. Curr Ther Res Clin Exp. 2019; 91: 25-32.

75. Zhu X, Ye G, Wang Z, Luo J, Hao X. Sub-anesthetic doses of ketamine exert antidepressant-like effects and upregulate the expression of glutamate transporters in the hippocampus of rats. Neurosci Lett. 2017; 639: 132-37.

76. Kalkman HO. Novel Treatment Targets Based on Insights in the Etiology of Depression: Role of IL-6 TransSignaling and Stress-Induced Elevation of Glutamate and ATP. Pharmaceuticals 2019; 12: 113.

77. Levine J, Panchalingam K, Rapoport A, Gershon S, McClure RJ, Pettegrew JW. Increased cerebrospinal fluid glutamine levels in depressed patients. Biol Psychiatr. 2000: 47: 586-93.

78. Frye MA, Tsai GE, Huggins T, Coyle JT, Post RM. Low cerebrospinal fluid glutamate and glycine in refractory affective disorder. Biol Psychiatr. 2007; 61: 162-66.

79. Garakani A, Martinez JM, Yehuda R, Gorman JM. Cerebrospinal fluid levels of glutamate and corticotropin releasing hormone in major depression before and after treatment. J Affect Disord. 2013; 146: 262-5.

80. Geddes SD, Assadzada S, Sokolovski A, Bergeron R, Haj-Dahmane S, Beïque JC. Time-dependent modulation of glutamate synapses onto 5-HT neurons by antidepressant treatment. Neuropharmacology. 2015; 95: 130-43.

81. Inoshita M, Umehara H, Watanabe SY, Nakataki M, Kinoshita M, Tomioka Y, et al. Elevated peripheral blood glutamate levels in major depressive disorder. Neuropsychiatr Dis Treat. 2018; 14: 945-53.

82. Madeira C, Vargas-Lopes C, Brandão CO, Reis T, Laks J, Panizzutti R, Ferreira ST. Elevated Glutamate and Glutamine Levels in the Cerebrospinal Fluid of Patients With Probable Alzheimer's Disease and Depression. Front Psychiatr. 2018; 9: 561.

83. Moriguchi S, Takamiya A, Noda Y, Horita N, Wada M, Tsugawa S, et al. Glutamatergic neurometabolite levels in major depressive disorder: a systematic review and meta-analysis of proton magnetic resonance spectroscopy studies. Mol Psychiatr. 2019; 24: 952-64.

84. Feyissa AM, Chandran A, Stockmeier CA, Karolewicz B. Reduced levels of NR2A and NR2B subunits of NMDA receptor and PSD-95 in the prefrontal cortex in major depression. Prog Neuropsychopharmacol Biol Psychiatr. 2009; 33:70-5.

85. Barnes SA, Sheffler DJ, Semenova S, Cosford NDP, Bespalov A. Metabotropic Glutamate Receptor 5 as a Target for the Treatment of Depression and Smoking: Robust Preclinical Data but Inconclusive Clinical Efficacy. Biol Psychiatr. 2018; 83: 955-62.

86. Kovačević T, Skelin I, Minuzzi L, Rosa-Neto P, Diksic M. Reduced metabotropic glutamate receptor 5 in the Flinders Sensitive Line of rats, an animal model of depression: an autoradiographic study. Brain Res Bull. 2012; 87: 406-12.

87. Abdallah CG, Hannestad J, Mason GF, Holmes SE, DellaGioia N, Sanacora G, et al. Metabotropic Glutamate Receptor 5 and Glutamate Involvement in Major Depressive Disorder: A Multimodal Imaging Study. Biol Psychiatry Cogn Neurosci Neuroimaging. 2017; 2: 449-56.

88. Karolewicz B, Feyissa AM, Chandran A, Legutko B, Ordway GA, Rajkowska G, et al. Glutamate receptors expression in postmortem brain from depressed subjects. Biol Psychiatr. 2009; 65 (Suppl): 177S.

89. Hasler G. Abnormal prefrontal glutamatergic and GABAeric systems in mood and anxiety disorders. Biol Psychiatr. 2009; 65 (Suppl): 176S-177S.

90. Deschwanden A, Karolewicz B, Feyissa AM, Treyer V, Ametamey SM, Johayem A, et al. Reduced metabotropic glutamate receptor 5 density in major depression determined by [11C]ABP688 PET and postmortem study. Am J Psychiatr. 2011; 168: 727-34.

91. Henter ID, de Sousa RT, Zarate CA Jr. Glutamatergic Modulators in Depression. Harv Rev Psychiatry. 2018; 26: 307-19. 
92. Feyissa AM, Woolverton WL, Miguel-Hidalgo JJ, Wang Z, Kyle PB, Hasler G, et al. Elevated level of metabotropic glutamate receptor $2 / 3$ in the prefrontal cortex in major depression. Prog Neuropsychopharmacol Biol Psychiatr. 2010; 34: 279-83.

93. Treccani G, Gaarn du Jardin K, Wegener G, Müller HK. Differential expression of postsynaptic NMDA and AMPA receptor subunits in the hippocampus and prefrontal cortex of the flinders sensitive line rat model of depression. Synapse. 2016; 70: 471-4.

94. Gray AL, Hyde TM, Deep-Soboslay A, Kleinman JE, Sodhi MS. Sex differences in glutamate receptor gene expression in major depression and suicide. Mol Psychiatr. 2015; 20: 1057-68.

95. Rong X, Xiong Z, Cao B, Chen J, Li M, Li Z. Case report of anti-N-methyl-D-aspartate receptor encephalitis in a middle-aged woman with a long history of major depressive disorder. BMC Psychiatr. 2017; 17 (1): 320 .

96. Karolewicz B, Szebeni K, Gilmore T, Maciag D, Stockmeier CA, Ordway GA. Elevated levels of NR2A and PSD-95 in the lateral amygdala in depression. Int J Neuropsychopharmacol. 2009; 12: 143-53.

97. Francija E, Petrovic Z, Brkic Z, Mitic M, Radulovic J, Adzic M. Disruption of the NMDA receptor GluN2A subunit abolishes inflammation-induced depression. Behav Brain Res. 2019; 359: 550-9.

98. Lai CH. Gray matter volume in major depressive disorder: a meta-analysis of voxel-based morphometry studies. Psychiatry Res. 2013; 211: 37-46.

99. Amidfar M, Woelfer M, Réus GZ, Quevedo J, Walter M, Kim YK. The role of NMDA receptor in neurobiology and treatment of major depressive disorder: Evidence from translational research. Prog Neuropsychopharmacol Biol Psychiatr. 2019; 94: 109668.

100. Gibbons AS, Brooks L, Scarr E, Dean B. AMPA receptor expression is increased post-mortem samples of the anterior cingulate from subjects with major depressive disorder. J Affect Disord. 2012; 136:1232-7.

101. Garibova TL, Gudasheva TA, Seredenin SB. A New Component in the Mechanism of Regulation of Endogenous Depressive-Like States. Dokl Biochem Biophys. 2019; 488: 324-6.

102. Yi ES, Oh S, Lee JK, Leem YH. Chronic stress-induced dendritic reorganization and abundance of synaptosomal PKA-dependent CP-AMPA receptor in the basolateral amygdala in a mouse model of depression. Biochem Biophys Res Commun. 2017; 486: 671-8.

103. Chourbaji S, Vogt MA, Fumagalli F, Sohr R, Frasca A, Brandwein C, et al. AMPA receptor subunit 1 (GluRA) knockout mice model the glutamate hypothesis of depression. FASEB J. 2008; 22: 3129-34.

104. Barbon A, Caracciolo L, Orlandi C, Musazzi L, Mallei A, La Via L, et al. Chronic antidepressant treatments induce a time-dependent up-regulation of AMPA receptor subunit protein levels. Neurochem Int. 2011; 59: 896-905.

105. Szegedi V, Juhász G, Zhang X, Barkóczi B, Qi H, Madeira A, et al. Tianeptine potentiates AMPA receptors by activating CaMKII and PKA via the p38, p42/44 MAPK and JNK pathways. Neurochem Int. 2011; 59: 1109-22.

106. Freudenberg F, Celikel T, Reif A. The role of $\alpha$-amino-3-hydroxy-5-methyl-4-isoxazolepropionic acid (AMPA) receptors in depression: central mediators of pathophysiology and antidepressant activity? Neurosci Biobehav Rev. 2015; 52: 193-206.

107. Duric V, Banasr M, Stockmeier CA, Simen AA, Newton SS, Overholser JC, et al. Altered expression of synapse and glutamate related genes in post-mortem hippocampus of depressed subjects. Int J Neuropsychopharmacol. 2013; 16: 69-82.

108. Möhler H. The GABA system in anxiety and depression and its therapeutic potential. Neuropharmacology. 2012; 62: 42-53.

109. Jaso BA, Niciu MJ, Iadarola ND, Lally N, Richards EM, Park M, et al. Therapeutic Modulation of Glutamate Receptors in Major Depressive Disorder. Curr Neuropharmacol. 2017; 15: 57-70.

110. Schule C, Nothdurfter C, Rupprecht R. The role of allopregnanolone in depression and anxiety. Prog Neurobiol. 2014; 113: 79-87.

111. Trifu S, Vladuti A, Popescu A. The neuroendocrinological aspects of pregnancy and postpartum depression. Acta Endocrinol (Buchar). 2019; 15: 410-5.

112. Farrant M, Nusser Z. Variations on an inhibitory theme: phasic and tonic activation of GABA(A) receptors. Nat Rev Neurosci 2005; 6: 215-29.

113. Walton N, Maguire J. Allopregnanolone-based treatments for postpartum depression: Why/how do they work? Neurobiol Stress. 2019; 11: 100198.

114. Azhar Y, Din AU. Brexanolone. StatPearls [Internet]. Treasure Island (FL): StatPearls Publishing, 2019. 
115. Kanes SJ, Colquhoun H, Doherty J, Raines S, Hoffmann E, Rubinow DR, et al. Open-label, proof-of-concept study of brexanolone in the treatment of severe postpartum depression. Hum. Psychopharmacol. 2017; 32 (2): e2576.

116. Kanes S, Colquhoun H, Gunduz-Bruce H, Raines S, Arnold R, Schacterle A, et al. Brexanolone (SAGE-547 injection) in post-partum depression: a randomised controlled trial. Lancet. 2017; 390: 480-9.

117. Meltzer-Brody S, Colquhoun H, Riesenberg R, Epperson CN, Deligiannidis KM, Rubinow DR, et al. Brexanolone injection in post-partum depression: two multicentre, double-blind, randomised, placebocontrolled, phase 3 trials. Lancet. 2018; 392: 1058-70.

118. Hutcherson TC, Cieri-Hutcherson NE, Gosciak MF. Brexanolone for postpartum depression. Am J Health Syst Pharm. 2020; 77: 336-45.

119. Fasipe OJ. The emergence of new antidepressants for clinical use: Agomelatine paradox versus other novel agents. IBRO Rep. 2019; 6: 95-110.

120. Zarate CA Jr, Payne JL, Quiroz J, Sporn J, Denicoff KK, Luckenbaugh D, Manji HK. An open label trial of riluzole in patients with treatment-resistant major depression. Am J Psychiatr. 2004; 161: 171-4.

121. Sanacora G, Kendell SF, Levin Y, Simen AA, Fenton LR, Coric V, Krystal JH. Preliminary evidence of riluzole efficacy in antidepressant-treated patients with residual depressive symptoms. Biol Psychiatry. 2007; 61: 822-5.

122. Wilkinson ST, Sanacora G. A new generation of antidepressants: an update on the pharmaceutical pipeline for novel and rapid-acting therapeutics in mood disorders based on glutamate/GABA neurotransmitter systems. Drug Discov Today. 2019; 24: 606-15.

123. Salardini E, Zeinoddini A, Mohammadinejad P, Khodaie-Ardakani MR, Zahraei N, Zeinoddini A, Akhondzadeh S. Riluzole combination therapy for moderate-to-severe major depressive disorder: A randomized, double-blind, placebo-controlled trial. J Psychiatr Res. 2016; 75: 24-30.

124. Yao R, Wang H, Yuan M, Wang G, Wu C. Efficacy and safety of riluzole for depressive disorder: A systematic review and meta-analysis of randomized placebo-controlled trials. Psychiatry Res. 2020; 284: 112750.

125. Kato T, Duman RS, Rapastinel A. A novel glutamatergic agent with ketamine-like antidepressant actions: Convergent mechanisms. Pharmacol Biochem Behav. 2020; 188: 172827.

126. Sanacora G, Johnson MR, Khan A, Atkinson SD, Riesenberg RR, Schronen JP, et al. Adjunctive Lanicemine (AZD6765) in Patients with Major Depressive Disorder and History of Inadequate Response to Antidepressants: A Randomized, Placebo-Controlled Study. Neuropsychopharmacology. 2017; 42: 844-53.

127. Hirota K, Lambert DG. Ketamine: new uses for an old drug? Br J Anaesth. 2011; 107: 123-6.

128. Rosenblat JD, Carvalho AF, Li M, Lee Y, Subramanieapillai M, McIntyre RS. Oral Ketamine for Depression: A Systematic Review. J Clin Psychiatr. 2019; 80 (3): 18r12475.

129. Pribish A, Wood N, Kalava A. A Review of Nonanesthetic Uses of Ketamine. Anesthesiol Res Pract. 2020; 5798285.

130. Liao Y, Tang YL, Hao W. Ketamine and international regulations. Am J Drug Alcohol Abuse. 2017; 43: 495504.

131. Carreno FR, Lodge DJ, Frazer A. Ketamine: Leading us into the future for development of antidepressants. Behav Brain Res. 2020; 383: 112532.

132. Widman AJ, McMahon LL. Disinhibition of CA1 pyramidal cells by low-dose ketamine and other antagonists with rapid antidepressant efficacy. Proc Natl Acad Sci USA. 2018; 115 (13): E3007-E3016.

133. Wang Y, Toledo-Rodriguez M, Gupta A, Wu C, Silberberg G, Luo J, Markram H. Anatomical, physiological and molecular properties of Martinotti cells in the somatosensory cortex of the juvenile rat. J Physiol. 2004; 561: 65-90.

134. Ali F, Gerhard DM, Sweasy K, Pothula S, Pittenger C, Duman RS, Kwan AC. Ketamine disinhibits dendrites and enhances calcium signals in prefrontal dendritic spines. Nat Commun. 2020; 11: 72.

135. Aleksandrova LR, Phillips AG, Wang YT. Antidepressant effects of ketamine and the roles of AMPA glutamate receptors and other mechanisms beyond NMDA receptor antagonism. J Psychiatry Neurosci. 2017; 42: 222-9.

136. Zhang JC, Li SX, Hashimoto K. R (-)-ketamine shows greater potency and longer lasting antidepressant effects than S (+)-ketamine. Pharmacol Biochem Behav. 2014; 116: 137-41.

137. Henley JM, Wilkinson KA. Synaptic AMPA receptor composition in development, plasticity and disease. Nat Rev Neurosci. 2016; 17: 337-50. 
138. Duman RS, Aghajanian GK, Sanacora G, Krystal JH. Synaptic plasticity and depression: new insights from stress and rapid-acting antidepressants. Nat Med. 2016; 22: 238-49.

139. Muthukumaraswamy SD, Shaw AD, Jackson LE, Hall J, Moran R, Saxena N. Evidence that Subanesthetic Doses of Ketamine Cause Sustained Disruptions of NMDA and AMPA-Mediated Frontoparietal Connectivity in Humans. J Neurosci. 2015; 35: 11694-706.

140. Zanos P, Gould TD. Mechanisms of ketamine action as an antidepressant. Mol Psychiatry. 2018; 23: 801-11.

141. Gould TD, Zarate CA Jr, Thompson SM. Molecular Pharmacology and Neurobiology of Rapid-Acting Antidepressants. Annu Rev Pharmacol Toxicol. 2019; 59: 213-36.

142. Ma Z, Zang T, Birnbaum SG, Wang Z, Johnson JE, Zhang CL, Parada LF. TrkB dependent adult hippocampal progenitor differentiation mediates sustained ketamine antidepressant response. Nat Commun. 2017; 8 (1): 1668.

143. Liu WX, Wang J, Xie ZM, Xu N, Zhang GF, Jia M, et al. Regulation of glutamate transporter 1 via BDNFTrkB signaling plays a role in the anti-apoptotic and antidepressant effects of ketamine in chronic unpredictable stress model of depression. Psychopharmacology (Berl). 2016; 233: 405-15.

144. Liu RJ, Lee FS, Li XY, Bambico F, Duman RS, Aghajanian GK. Brain-derived neurotrophic factor Val66Met allele impairs basal and ketamine-stimulated synaptogenesis in prefrontal cortex. Biol Psychiatry. 2012; 71: 996-1005.

145. Yang C, Shirayama Y, Zhang JC, Ren Q, Yao W, Ma M, et al. R-ketamine: a rapid-onset and sustained antidepressant without psychotomimetic side effects. Transl Psychiatry. 2015; 5 (9): e632.

146. Lepack AE, Fuchikami M, Dwyer JM, Banasr M, Duman RS. BDNF release is required for the behavioral actions of ketamine. Int J Neuropsychopharmacol. 2014; 18 (1): pii: pyu033.

147. Strasburger SE, Bhimani PM, Kaabe JH, Krysiak JT, Nanchanatt DL, Nguyen TN, et al. What is the mechanism of Ketamine's rapid-onset antidepressant effect? A concise overview of the surprisingly large number of possibilities. J Clin Pharm Ther. 2017; 42: 147-54.

148. Huang YJ, Lane HY, Lin CH. New Treatment Strategies of Depression: Based on Mechanisms Related to Neuroplasticity. Neural Plast. 2017; 4605971.

149. Abdallah CG, Sanacora G, Duman RS, Krystal JH. Ketamine and rapid-acting antidepressants: a window into a new neurobiology for mood disorder therapeutics. Annu Rev Med. 2015; 66: 509-23.

150. Wei Y, Chang L, Hashimoto K. A historical review of antidepressant effects of ketamine and its enantiomers. Pharmacol Biochem Behav. 2020; 190: 172870.

151. Tan S, Wang Y, Chen K, Long Z, Zou J. Ketamine Alleviates Depressive-Like Behaviors via DownRegulating Inflammatory Cytokines Induced by Chronic Restraint Stress in Mice. Biol Pharm Bull. 2017; 40: 1260-7.

152. Chen MH, Li CT, Lin WC, Hong CJ, Tu PC, Bai YM, et al. Rapid inflammation modulation and antidepressant efficacy of a low-dose ketamine infusion in treatment-resistant depression: A randomized, double-blind control study. Psychiatry Res. 2018; 269: 207-11.

153. Kokkinou M, Ashok AH, Howes OD. The effects of ketamine on dopaminergic function: meta-analysis and review of the implications for neuropsychiatric disorders. Mol Psychiatr. 2018; 23: 59-69.

154. Witkin JM, Monn JA, Schoepp DD, Li X, Overshiner C, Mitchell SN, et al. The Rapidly Acting Antidepressant Ketamine and the mGlu2/3 Receptor Antagonist LY341495 Rapidly Engage Dopaminergic Mood Circuits. J Pharmacol Exp Ther. 2016; 358: 71-82.

155. Fukumoto K, Iijima M, Chaki S. The Antidepressant Effects of an mGlu2/3 Receptor Antagonist and Ketamine Require AMPA Receptor Stimulation in the mPFC and Subsequent Activation of the 5-HT Neurons in the DRN. Neuropsychopharmacology. 2016; 41: 1046-56.

156. Pham TH, Mendez-David I, Defaix C, Guiard BP, Tritschler L, David DJ, Gardier AM. Ketamine treatment involves medial prefrontal cortex serotonin to induce a rapid antidepressant-like activity in BALB/cJ mice. Neuropharmacology. 2017; 112 (Pt A) :198-209.

157. Fukumoto K, Iijima M, Funakoshi T, Chaki S. Role of 5-HT1A Receptor Stimulation in the Medial Prefrontal Cortex in the Sustained Antidepressant Effects of Ketamine. Int J Neuropsychopharmacol. 2018; 21: 371-81.

158. Sial OK, Parise EM, Parise LF, Gnecco T, Bolaños-Guzmán CA. Ketamine: The final frontier or another depressing end?. Behav Brain Res. 2020; 383: 112508.

159. Williams NR, Heifets BD, Blasey C, Sudheimer K, Pannu J, Pankow H, et al. Attenuation of Antidepressant Effects of Ketamine by Opioid Receptor Antagonism. Am J Psychiatry. 2018; 175: 1205-15. 
160. Williams NR, Heifets BD, Bentzley BS, Blasey C, Sudheimer KD, Hawkins J, et al. Attenuation of antidepressant and antisuicidal effects of ketamine by opioid receptor antagonism. Mol Psychiatr. 2019; 24: 1779-86.

161. Yoon G, Petrakis IL, Krystal JH. Association of Combined Naltrexone and Ketamine With Depressive Symptoms in a Case series of Patients With Depression and Alcohol Use Disorder. JAMA Psychiatr. 2019; 76: 337-8.

162. Marton T, Barnes DE, Wallace A, Woolley JD. Concurrent Use of Buprenorphine, Methadone, or Naltrexone Does Not Inhibit Ketamine's Antidepressant Activity. Biol Psychiatr. 2019; 85 (12): e75-e76.

163. Mathew SJ, Rivas-Grajales AM. Does the opioid system block or enhance the antidepressant effects of ketamine? Chronic Stress (Thousand Oaks). 2019; 3: 3: 2470547019852073.

164. Miller JJ. Ketamine/esketamine: Putative mechanisms of action. Curr Psychiatr. 2020; 19: 32-6.

165. Sofia RD, Harakal JJ. Evaluation of ketamine $\mathrm{HCl}$ for anti-depressant activity. Arch Int Pharmacodyn Ther. 1975; 214: 68-74.

166. Domino EF. Taming the ketamine tiger. 1965. Anesthesiology. 2010; 113: 678-84.

167. López-Muñoz F, Álamo C, Domino EF. History of Psychopharmacology. Arlington: NPP Books, 2014.

168. Berman RM, Cappiello A, Anand A, Oren DA, Heninger GR, Charney DS, Krystal JH. Antidepressant effects of ketamine in depressed patients. Biol Psychiatr. 2000; 47: 351-4.

169. Zarate Jr CA, Singh JB, Carlson PJ, Brutsche NE, Ameli R, Luckenbaugh DA, et al. A randomized trial of an N-methyl-D-aspartate antagonist in treatment-resistant major depression. Arch Gen Psychiatr. 2006; 63: 856-64.

170. Zarate CA Jr. Ketamine: a new chapter in antidepressant development. Braz J Psychiatry. 2020; May 11: S1516-44462020005013205.

171. Phillips JL, Norris S, Talbot J, Birmingham M, Hatchard T, Ortiz A, et al. Single, repeated, and maintenance ketamine infusions for treatment-resistant depression: a randomized controlled trial. Am J Psychiatr. 2019; 176: 401-9.

172. Domany Y, Shelton RC, McCullumsmith CB. Ketamine for acute suicidal ideation. An emergency department intervention: A randomized, double-blind, placebo-controlled, proof-of-concept trial. Depress Anxiety. 2020; 37: 224-33.

173. Price RB, Iosifescu DV, Murrough JW, Chang LC, Al Jurdi RK, Iqbal SZ, et al. Effects of ketamine on explicit and implicit suicidal cognition: a randomized controlled trial in treatment-resistant depression. Depress Anxiety. 2014; 31: 335-43.

174. Ballard ED, Wills K, Lally N, Richards EM, Luckenbaugh DA, Walls T, et al. Anhedonia as a clinical correlate of suicidal thoughts in clinical ketamine trials. J Affect Disord. 2017; 218: 195-200.

175. Kryst J, Kawalec P, Pilc A. Efficacy and safety of intranasal esketamine for the treatment of major depressive disorder. Exp Opin Pharmacother. 2020; 21: 9-20.

176. Andrade C. Intranasal drug delivery in neuropsychiatry: Focus on intranasalketamine for refractory depression. J Clin Psychiatr. 2015; 76: e628-31. 21.

177. Singh JB, Fedgchin M, Daly E, Xi L, Melman C, De Bruecker G, et al. Intravenous Esketamine in Adult Treatment-Resistant Depression: A Double-Blind, Double-Randomization, Placebo-Controlled Study. Biol Psychiatr. 2016; 80: 424-31.

178. Wajs E, Aluisio L, Holder R, Daly EJ, Lane R, Lim P, et al. Esketamine Nasal Spray Plus Oral Antidepressant in Patients With Treatment-Resistant Depression: Assessment of Long-Term Safety in a Phase 3, OpenLabel Study (SUSTAIN-2). J Clin Psychiatr. 2020; 81 (3): 19m12891.

179. Daly EJ, Trivedi MH, Janik A, Li H, Zhang Y, Li X, et al. Efficacy of Esketamine Nasal Spray Plus Oral Antidepressant Treatment for Relapse Prevention in Patients With Treatment-Resistant Depression: A Randomized Clinical Trial. JAMA Psychiatr. 2019; 76: 893-903.

180. Popova V, Daly EJ, Trivedi M, Cooper K, Lane R, Lim P, et al. Efficacy and Safety of Flexibly Dosed Esketamine Nasal Spray Combined With a Newly Initiated Oral Antidepressant in Treatment-Resistant Depression: A Randomized Double-Blind Active-Controlled Study. Am J Psychiatr. 2019; 176: 428-38.

181. Kim J, Farchione T, Potter A, Chen Q, Temple R. Esketamine for Treatment-Resistant Depression - First FDA-Approved Antidepressant in a New Class. N Engl J Med. 2019; 381: 1-4.

182. Zheng W, Cai DB, Xiang YQ, Zheng W, Jiang WL, Sim K, et al. Adjunctive intranasal esketamine for major depressive disorder: A systematic review of randomized double-blind controlled-placebo studies. J Affect Disord. 2020; 265: 63-70. 
183. Fu DJ, Ionescu DF, Li X, Lane R, Lim P, Sanacora G, et al. Esketamine Nasal Spray for Rapid Reduction of Major Depressive Disorder Symptoms in Patients Who Have Active Suicidal Ideation With Intent: DoubleBlind, Randomized Study (ASPIRE I). J Clin Psychiatr. 2020; 81 (3): pii: $19 \mathrm{~m} 13191$.

184. Ionescu DF, Canuso CM, Fu DF, Qiu X, Lane R, Lim P, et al. Esketamine nasal spray for rapid reduction of major depressive disorder symptoms in patientsat imminent risk for suicide: ASPIRE-2 study. Copenhagen: 32nd ECNP, 2019, 31.

185. Doherty T, Wajs E, Melkote R, Miller J, Singh JB, Weber MA. Cardiac Safety of Esketamine Nasal Spray in Treatment-Resistant Depression: Results from the Clinical Development Program. CNS Drugs. 2020; 34: 299-310.

186. González-Pinto A. Esketamina intranasal: un nuevo abordaje para el tratamiento de la depresión resistente al tratamiento. Psiquiatr Biol. 2020; 27: 9-15.

187. Pochwat B, Pałucha-Poniewiera A, Szewczyk B, Pilc A, Nowak G. NMDA antagonists under investigation for the treatment of major depressive disorder. Exp Opin Investig Drugs. 2014; 23: 1181-92.

(C) 2020 por los autores; Esta obra está sujeta a la licencia de Reconocimiento 4.0

Internacional de Creative Commons. Para ver una copia de esta licencia, visite http://creativecommons.org/licenses/by-nc-nd/4.0/. 